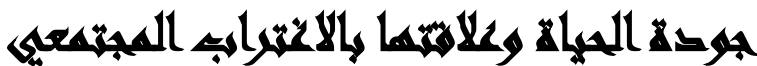

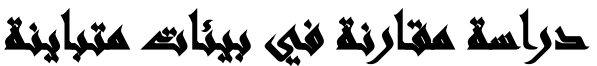

[^]

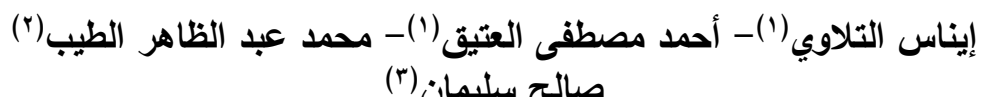

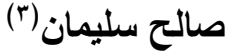

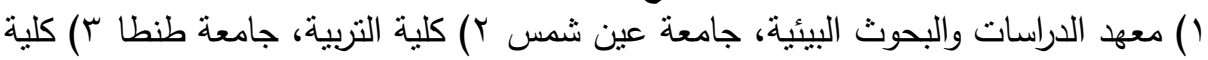

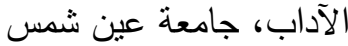

\section{المستקلص}

يتمثل هدف الدراسة في محاولة الكثف عن مدى وجود فروق بين أفراد عينة الدراسة من

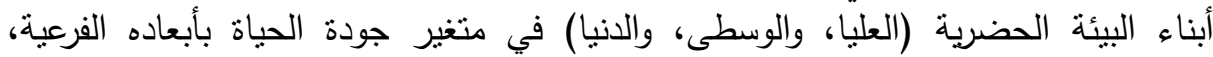

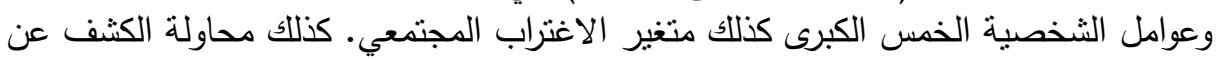

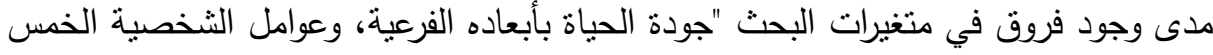

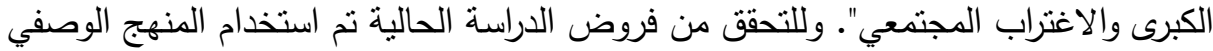

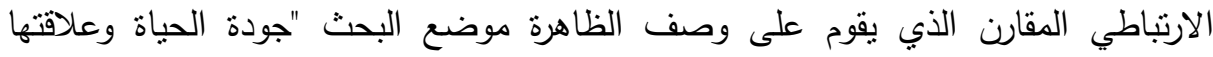

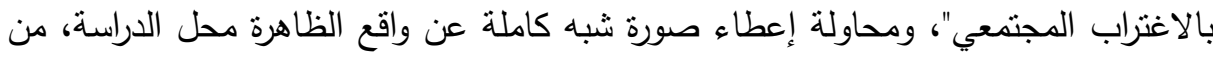

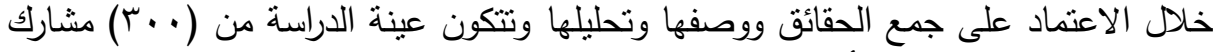

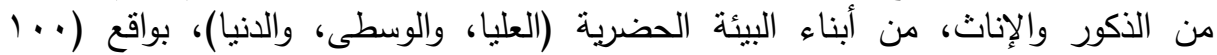

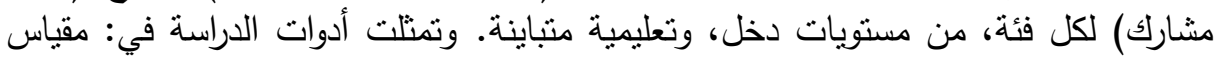

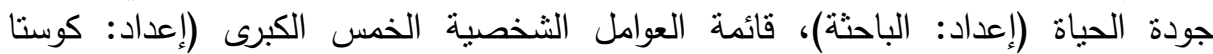
وماكري)، مقياس الاغتراب المجتمعي (إعداد: الباحثة).

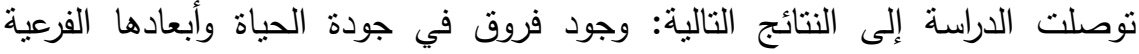

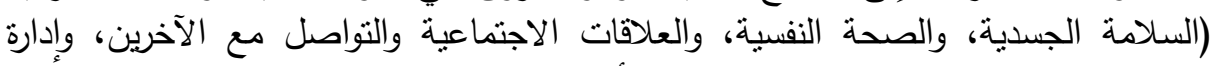

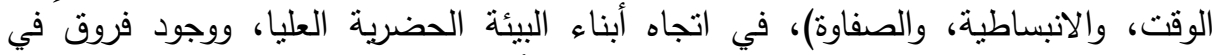

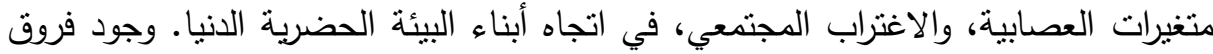

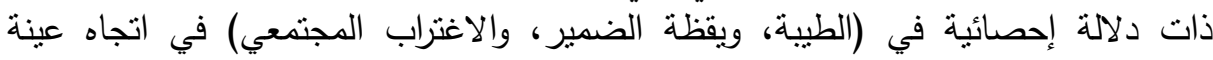

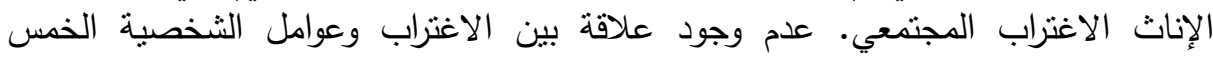

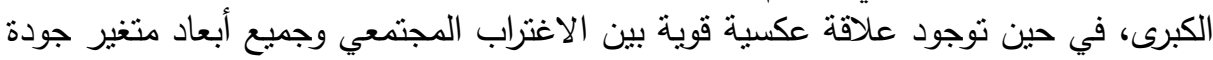

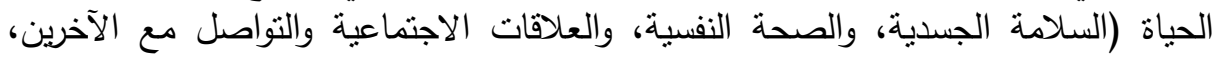

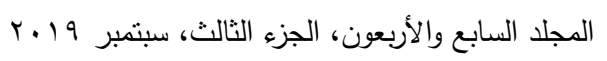


وإدارة الوقت، وكذللك الدرجة الكلية لجودة الحياة). وهذا يثير إلى احتمالية أن تزداد معدلات

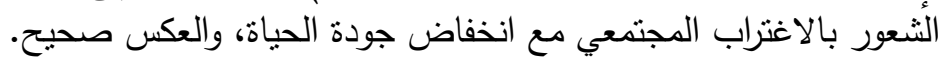

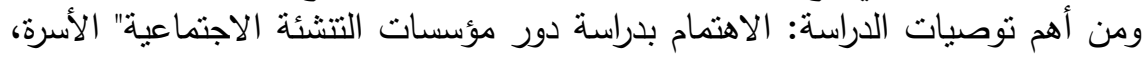

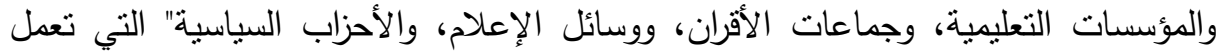

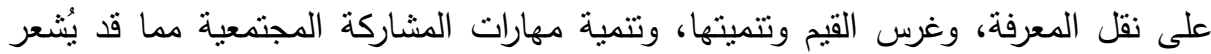

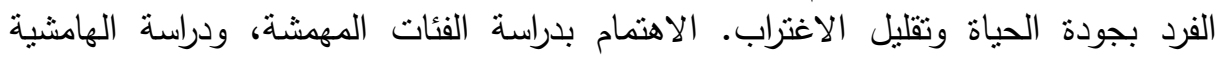
الاجتماعية باعنبارها إطار لتفسير العنف والتطرف الذي قد ينجم عن الثعور بالاغنراب.

\section{Ianax}

يعيش الإنسان في مجتمع يتسم بالتغير السريع على كافة المستويات، ويسعى دائمًا الى إيجاد مستوى من الرضا النفسي من أجل أن يحيا حياة نفسية سليمة، فحياة الانسان المعاصرة

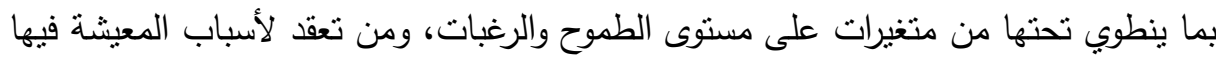

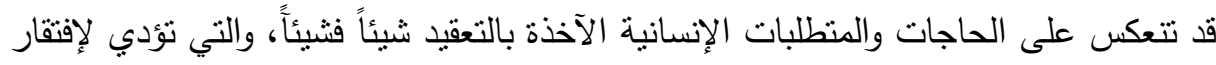
الإنسان الى حالة الاستقرار النفسي والذي ينعكس سلباً على شعوره بالأمان والاطمئنان.

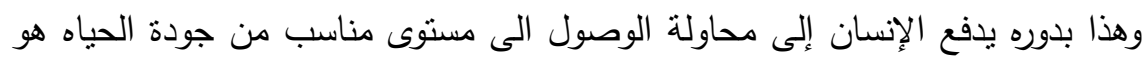
ما يسعى اليه الفرد من أجل أن يستمتع بالحياة ومع الآخرين الذين يشاركونه فيها وبالتالي

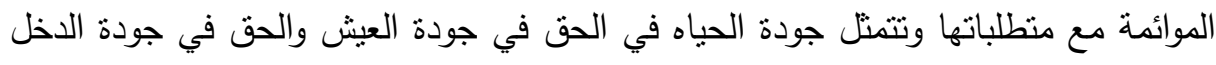

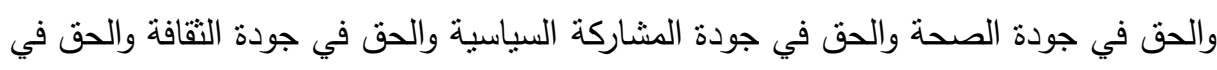
جودة الامن والحق في جودة البيئة.

وتعبر جودة الحياة عن التغير النفسي الاجتماعي الإيجابي الذي يحدث في استجابة

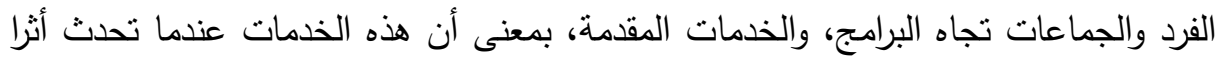
إيجابيا يعبر عن الفاعلية الإثباعية للسلوك في الاتجاه الصحيح، فإن ذلك هو ولهيات معيار

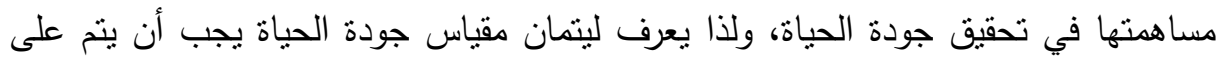

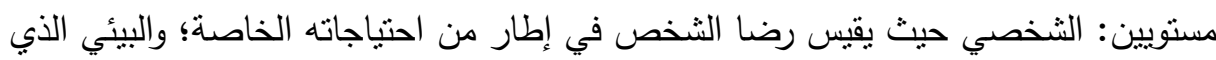

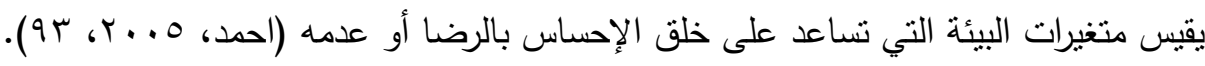

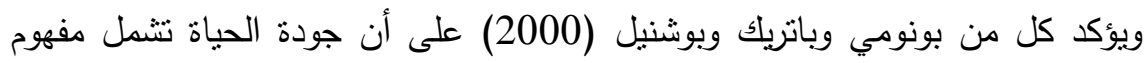
اوسع يتأثر بجوانب متداخلة من النواحي الذاتية والموضوعية، مرنبطة بالحالة الصحية والحالة 
النفسية للفرد، ومدى الاستقلال الذي يتمتع به والعلاقات الاجتماعية التي يكونها، فضلا عن

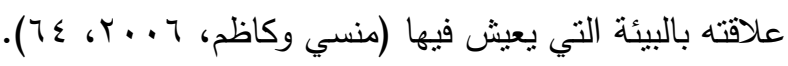

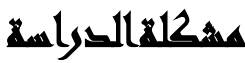

تعد جودة الحياة هدفا أساسيا لكل شخص، لذا تطور اهتمام علم النفس في السنوات

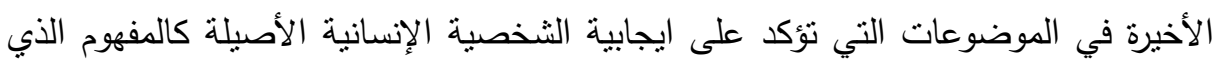

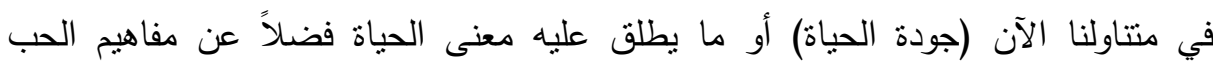
والمسئولية وغيرها. ويثدد علم النفس الإنساني على ضرورة إن إن تكون الحياة الداخلية

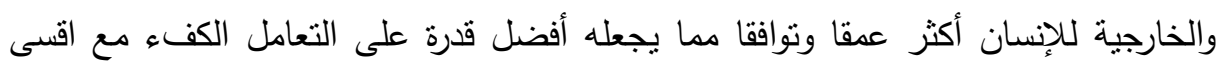
ظروف الحياة المحيطة به.

وعن سمات الثخصية التي يتسم بها الفرد هي التي تجعله شعوره بجودة حياته من عدمه ومن ثم الوقاية من خطر الإصابة بالاضطرابات النفسية. ولقد احتلت الثخصية الانسانية والعوامل المؤثرة في تكوينها مكانة هامة في الدراسات النفسية والاجتماعية وذللك بلإنه

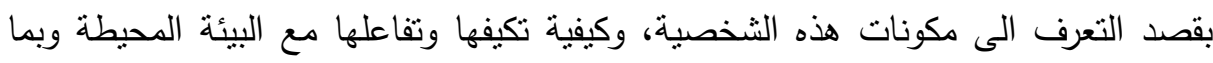
ينيح نمو الثخصية وتطورها. وعلى الرغم من الاتفاق على وحدة هذه الثخصية وتكاملها

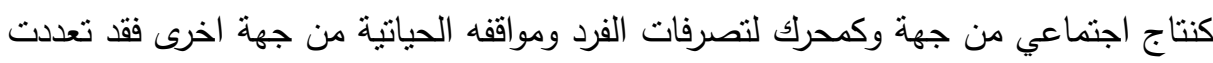
تعريفاتها تبعا للنظر اليها من جوانب متعددة. وقد أيقن علماء نفس الثخصية بالحاجة الماسة الى نموذج وصفي او تصنيف بشكل الابعاد الاساسية للشخصية الانسانية عن طريق تجميع الصفات المرتبطة معا، وتصنيفها

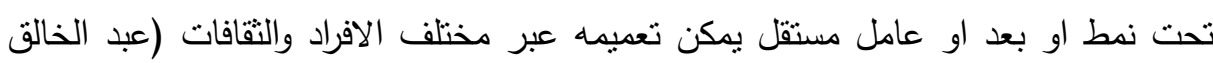

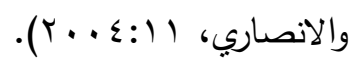

وفي ضوء ذللك يمكننا القول بأن لجوء الأفراد للسلوك المنحرف إنما قد ينجم عن شعوره

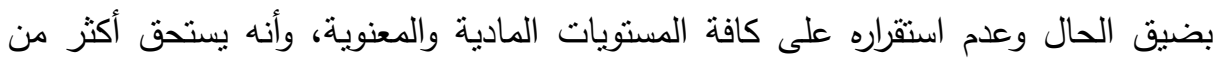

$$
\text { المجلد السابع والأربعون، الجزء الثالث، سبتمبر } 19 \text { ــ إب }
$$


وضعه الراهن بكثير وأن المجتمع لا يقدر قدراته وامكاناته. فذللك الفرد يكون بمثابة فريسة

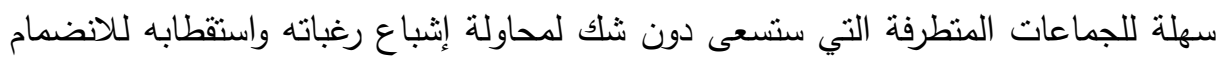
اليها، وهنا قد يتوحد ذللك الفرد مع تللك الجماعات فيؤمن بأفكارها ومعتقداتها ويدافع عنها بل دئل

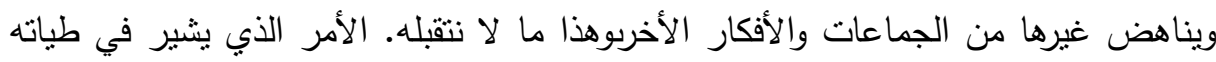

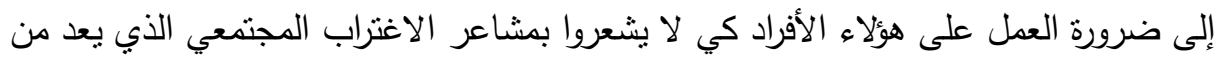

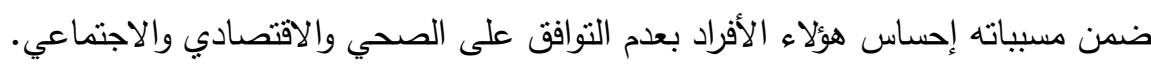
وترجع أهمية دراسة الاغتراب في فهم العديد من الظواهر المرنبطة بالسلوك المضاد

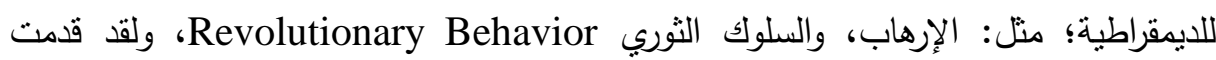

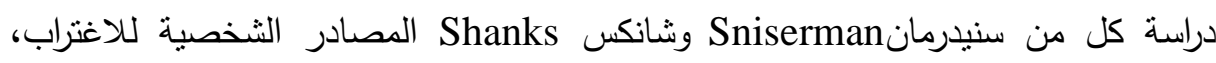
فالمصادر الثخصية؛ مثل: الدخل الثخصي، والتعليم، والعمر، والجنس ترتبط بالثعور بالغربة. (Pantoja A. \& Segura G.: 2002, P.3).

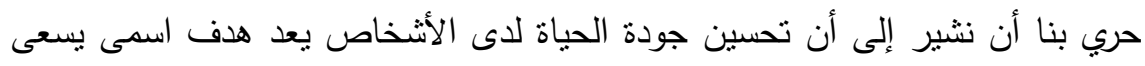

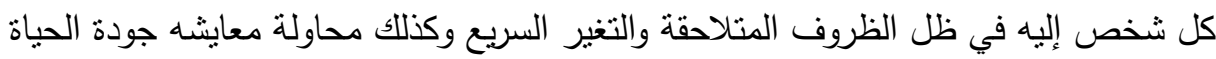
والثعور بتحسين الحال والتوافق النفسي والاجتماعي مما يقتضي صحة نفسية إيجابية

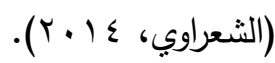
وفي ضوء ذلك يسعى البحث الراهن إلى محاولة التعرف على العلاقة بين جودة الحياة

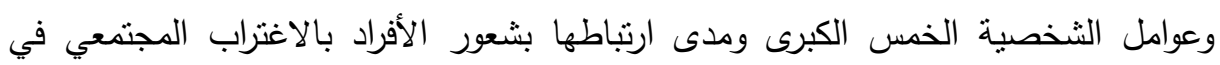
بيئات ثقافية متباينة.

\section{أهساهن السراسما}

• محاولة الكثف عن مدى وجود فروق بين أفراد عينة الدراسة من أبناء البيئة الحضرية (العليا، والوسطى، والدنيا) في متغير جودة الحياة بأبعاده الفرعية.

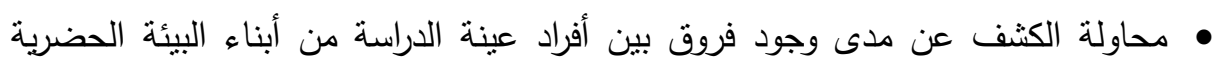
(العليا، والوسطى، والدنيا) في متغير الاغتراب المجتمعي. 
• محاولة الكثف عن مدى وجود فروق بين أفراد عينة الدراسة من أبناء البيئة الحضرية (العليا، والوسطى، والدنيا) في عوامل الثخصية الخمس الكبرى. • محاولة الكثف عن مدى وجود فروق في متغيرات الدراسة جودة الحياة بأبعاده الفرعية، وعنة

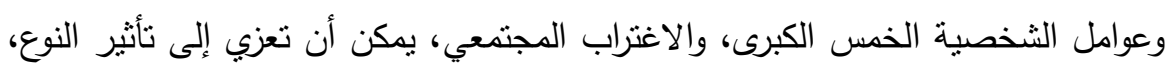
ومستوى الدخل، والمستوى التعليمي، لدى أفراد العينة الكلية.

\section{هروضر الفواسم}

• توجد فروق بين أفراد عينة الدراسة من أبناء البيئة الحضرية (العليا، والوسطى، والدنيا) في متغير جودة الحياة بأبعاده الفرعية. توجد فروق بين أفراد عينة الدراسة من أبناء البيئة الحضرية (العليا، والوسطى، والدئنيا) في متغير الاغتراب المجتمعي. توجد فروق بين أفراد عينة الدراسة من أبناء البيئة الحضرية (العليا، والوسطى، والدنيا) في متغير عوامل الثخصية الخمس الكبرى.

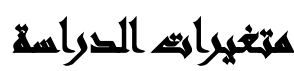

جودة الحياة: تعرف جودة الحياة على أنها شعور الفرد بمشاعر الصحة النفسية والمتمثلة في تمتعه بقدٍٍ وافٍ من السعادة والتفاؤل مع سلامة صحته الجسدية في ظل بيئة صحية

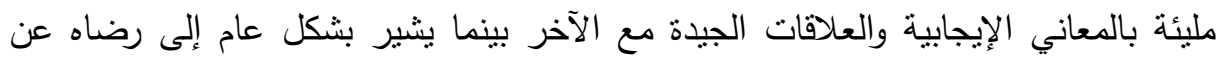

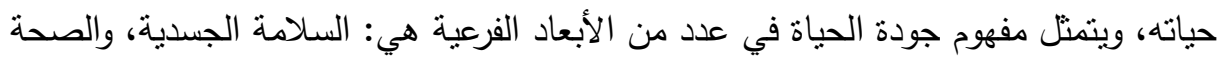

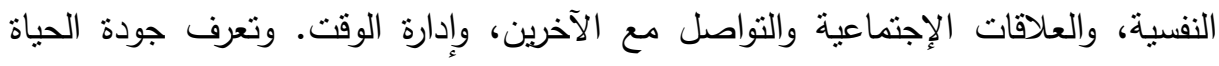
إجرائًا بالدرجة التى يحصل عليها المشارك فى مقياس جودة الحياة. 
عوامل الشخصية الخمس الكبرى: تعريف (كوستا وماكري، ب99 1): النموذج من سمات الثخصية تأخذ من خمس سمات حرجة هي: "العصابية، الانبساطية، الصفاوة، الطيبة، يقظة

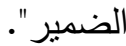

يعرف ماكري وجون (McCrae \& John: 1992, p.175) نموذج عوامل الشخصية الخمس بأنه تتظيم هرمي لسمات الثخصية يتضمن خمسة أبعاد أساسية هي: الانبساطية Extraversion و والعصابية Neuroticism، ويقظة الضمير Conscientiousness،

و المقبولية Agreeablenes الانفتاح على الخبرة Openness to Experience. الاغتراب المجتمعي: يعرف مفهوم الاغتراب Alienation على أنه شعور الفرد بالاففسال والعزلة عن مجريات الأمور التي تجري داخل المجتمع مع إحساسه برفض القيم والمعايير

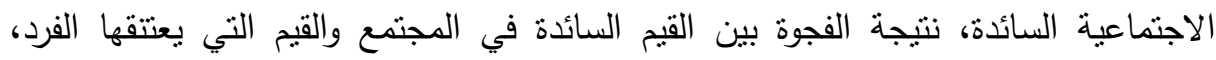
وبالتالي يشعر بعدم قدرته على التأثير في مجريات الأمور الخاصة به أو تشكيل الأحداث العامة في مجتمعه، فيسلك أحد أمرين: إما أن يحجم عن المشاركة في الحياة الاجتماعية وهنا قد نظهر السلبية واللامبالاة، أو أن يشارك مشاركة سلبية وهنا يكون عرضة لهنة للانضمام للجماعات المنطرفة، وقد نظهر هنا إثكالية الدولة الموازية ويختل البناء الاجتماعي للدولة.

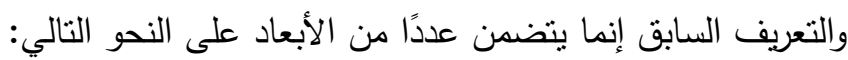
العزلة الاجتماعية Social isolation: وهي شعور ينتاب الفرد بالعزلة والانفصال عن عن عندئ الآخرين، ورفض فكرة الانتماء للمجتمع الذي يعيش فيه. اللامعيارية Normlessness: وهي إحساس الفرد بوجود خلل في تطبيق القوانين والمعايير الأخلاقية وأنها تتفاوت بين الموضوع والآخر ولذلك فهو رافض لها ويسعى جاهذًا للخروج عليها لعدم افتتاعه بها. العجز Powerlessness: إحساس الفرد بعدم قدرته على تغيير الأحداث المحيطة به في

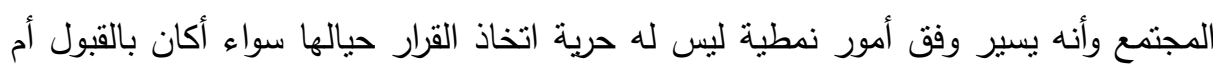

اللامعنى Meaninglessness: وهو شعور الفرد بأن الحياة لا قيمة لها وأنها خالية من

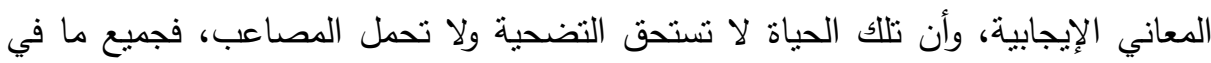


الحياة قد فقد معقوليته ودلالته بالنسبة له. ويعرف الاغتراب إجرائًاً بأنه الدرجة التى يحصل عليها المشارك فى مقياس الاغتراب كما تقيسه عبارات المقياس.

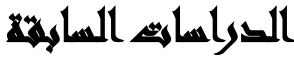

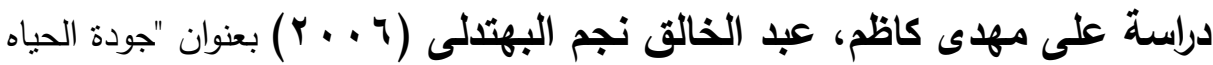
لدى طلبة الجامعه العمانيين والليبيين - دراسة ثقافيه مقارنه". فقد هدفت لمعرفة مستوى جودة الحياة لدى طلبة الجامعة في كل من سلطنة عمان والجماهيرية الليبية، ودور متغير البلد والنوع والتخصص الدراسي في جودة الحياة من عمان. وتوصلت الدراسة إلى النتائج التالية: مستوى جودة الياة هن عمان، الحياة كان مرتفعا في بعدين هما جودة الحياة الأسرية والاجتماعية، ومتوسطاً في بعدين هما جودة الصحة العامة، وجودة شغل وقت الفراغ، ومنخفضاً في بعدين هما جودة الصحة النفسية وجودة الجانب العاطفي.

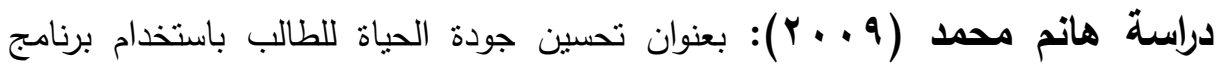
إرشادي قائم على نظرية الاختيار لاى طالبات الثانوي بمدينة الاسماعيلية. وتكونت عينة الدراسة من ( (Y) طالب واستخدام مقياس جودة الحياة من إعداده.

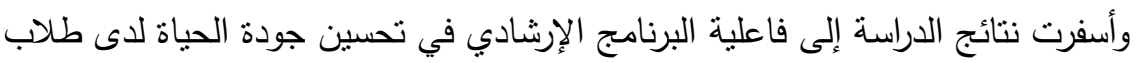

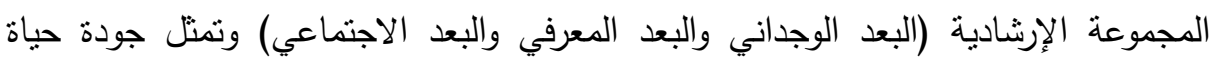
الطالب الذاتية، وفي أبعاد (بيئة الفصل أو المساندة الاجتماعية وأدوار المعلم). دراسة محمد حامد إبراهيم الهنداوي (11 (Y): بعنوان الدعم الاجتماعي وعلاقته بمستوى الرضا عن جودة الحياة لدى المعاقين حركيا بمحافظات غزة. وتهدف معرفة علاقة

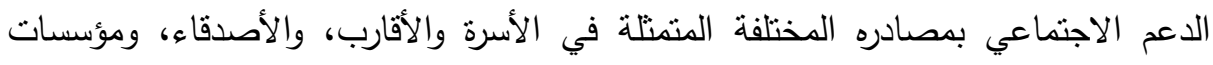

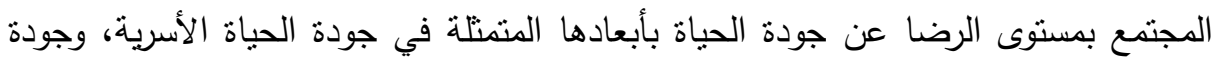

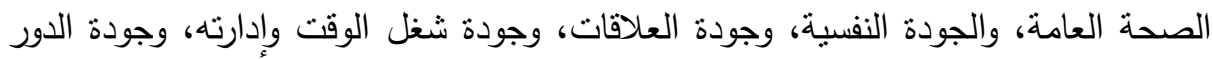
الاجتماعي، والجودة المهنية، وجودة الحياة الزوجية لدى المعاقين حركيًا.

$$
\text { المجلد السابع والأربعون، الجزء الثالث، سبتمبر } 9 \text {. }
$$


وقد توصلت الدراسة إلى مجموعة من النتائج من أهمها: توجد علاقة ذات دلالة

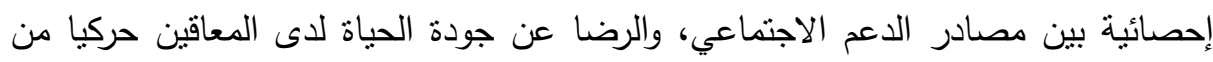
أفراد العينة. كما توجد علاقة ذات دلالة إحصائية بين الدعم الاجتماعي بأبعاده ودرجتها لكلية، والرضا عن جودة الحياة لدى المعاقين حركيا من أفراد العينة.

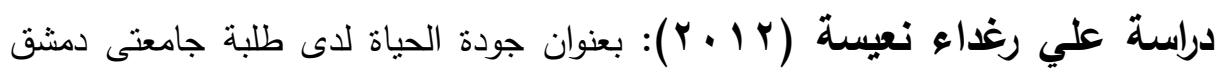

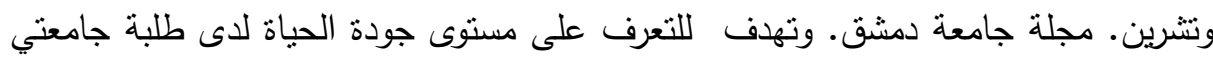
دمشق وتترين حسب تنغيرات البلد المحافظة: "دمثق واللاذقية"، والنوع الاجتماعي" ذكر ، أنثى"، والتخصص"علوم نظرية، علوم تطبيقية" للتعرف على جودة الحياة لدى عينة من هاتين الجامعتين. ومن أهم النتائج: وجود مستوى مندنٍ من جودة الحياة الجامعية لدى طلبة كل من جامعتي دمشق وتشرين. وعدم وجود علاقة دالة إحصائيا بين دخل الأسرة وأبعاد جودة الحياة.

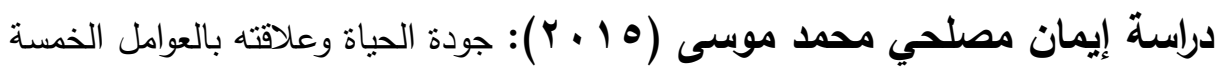
الكبرى للشخصية والكفاءة الذاتية لدى عينة من المرأة العاملة. رسالة ماجستير تهدف للتعرف على العلاقة بين جودة الحياة والعوامل الخمسة الكبرى للثخصية لدى المرأة العاملة، كذلك ملكئل العلاقة بين جودة الحياة والكفاءة الذاتية لدى المرأة العاملة. واعتمدت الدراسة على على المنهج

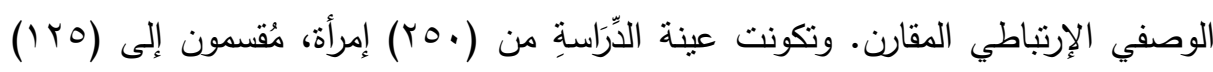

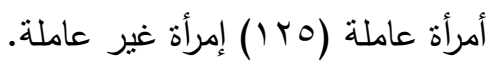
وأظهرت النتائج وجود علاقة بين جودة الحياة والعوامل الخمسة الكبرى للشخصية لاهى عاده المرأة العاملة. كذلك وجود علاقة بين جودة الحباة والكفاءة الذاتية لدى المرأة العاملة.

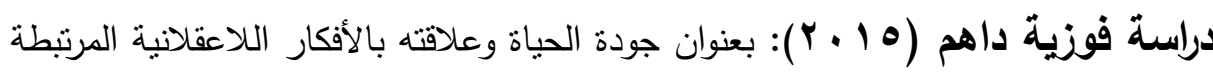
بقلق الامتحان لدى تلاميذ السنة الثالثة ثانوي، حيث تفترض الدراسة وجود علاقة بين جودة الحياة والأفكار اللاعقلانية المرتبطة بقلق الامتحان لدى أفراد عينة البحث.

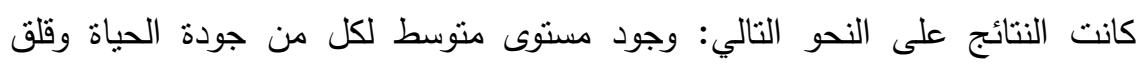
الامتحان لدى أفراد العينة. لا نوجد علاقة بين جودة الحياة والأفكار اللاعقلانية المرتبطة بقلق هن

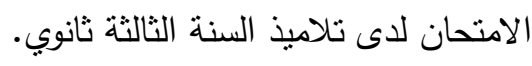




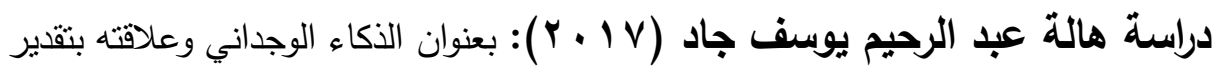

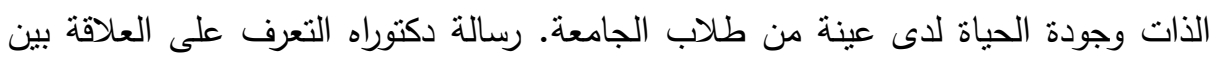

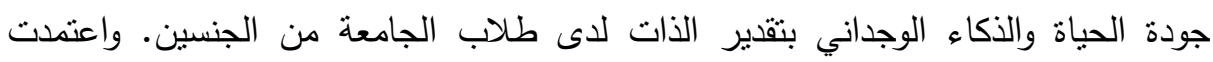
الدراسة على المنهج الوصفي الارتباطي المقارن.

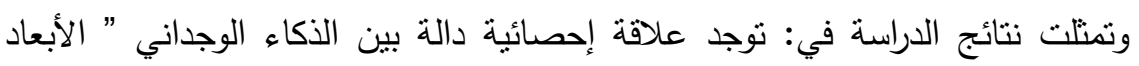

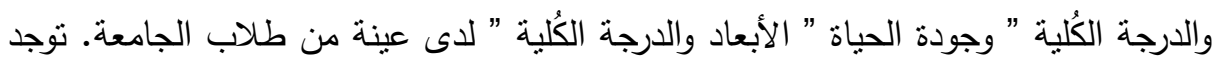

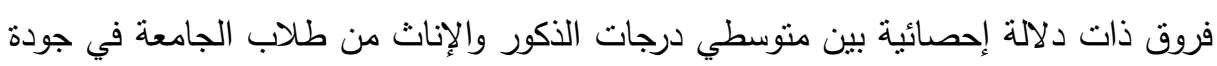

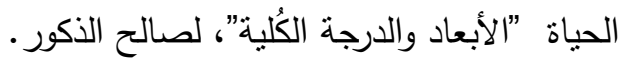

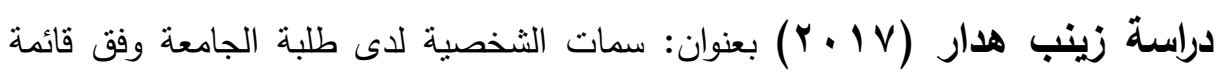
العوامل الخمسة الكبرى للثخصية لكوستا وماكري دراسة مقارنة بين الطلبة ذوي التفكير الإيجابي وذوي التفكير السلبي بجامعة غرداية. كما اوضحت النتائج وجود فروق ذات دلالة إحصائية تعزى لـتغير الجنس في السمات

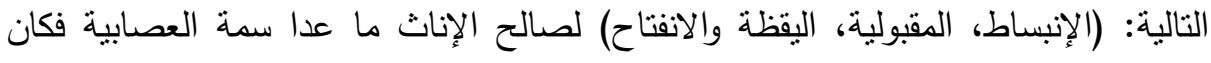

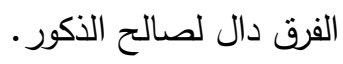

\section{الإطار اللنظيه}

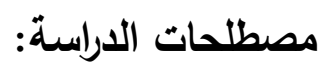

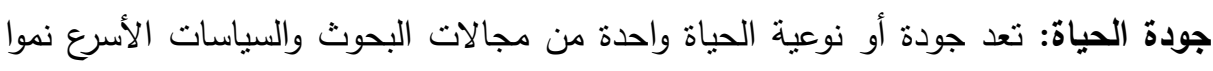

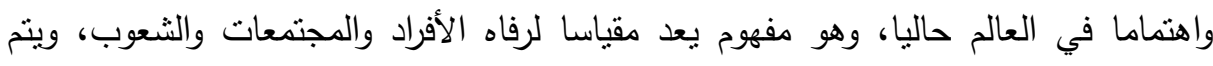

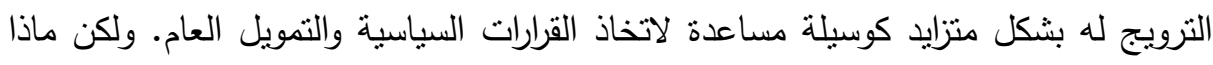
يعني هذا الدفوم، وكيف يمكن تفعيله؟

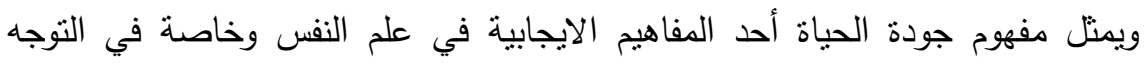
الإنساني الوجودي بعد إن حرر فرانكل .Frankl V. هذا الدفهوم من أصوله الفكرية والفلسفية 
ومنحه إمكانية التوظيف الإجرائي موضوعا جديرا بالبحث العلمي في علم النفس بعد الحرب

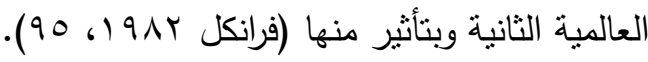
وقد بدأ في النصف الثاني من القرن العشرين الاهتمام بجودة الحياة كمفهوم مرنبط بعلم

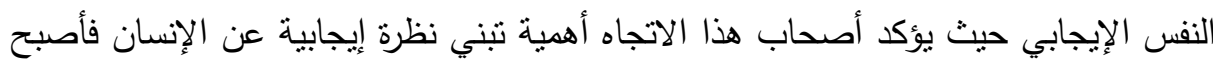

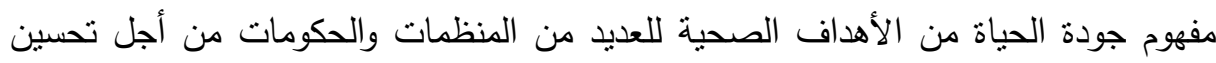
نوعية الحياة وتتمية التوقعات الايجابية لدى الثعوب (Ring, 2007: 178)

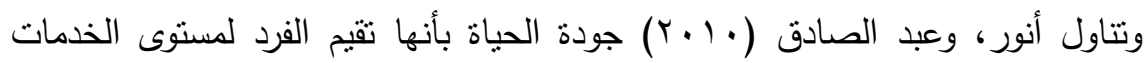

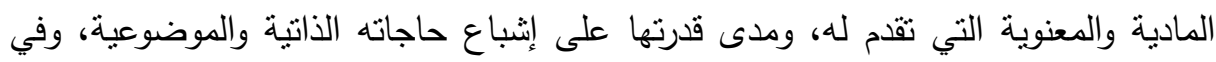
سياق الإطار الثقافي والقيمي الذي يعيش فيه، وانعكاس ذلك على التى حالته الصحية والنفسية وعلاقاته الاجتماعية وتوافقه مع البيئة المحيطة. وتعرف الباحثة جودة الحياة على أنها شعور الفرد بمشاعر الصحة النفسية والمتمثلة في

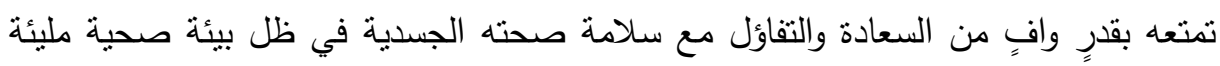
بالمعاني الإيجابية والعلاقات الجيدة مع الآخرينبما يشير بشكل عام إلى رضاه عند عن حياته. عوامل الشخصية الخمس الكبرى: احتلت الثخصية الانسانية والعوامل المؤثرة في تكوينها مكانة هامة في الدراسات النفسية والاجتماعية وذلك بقصد التعرف الى مكونات هذه الثخصية، وكيفية تكيفها وتفاعلها مع البيئة المحيطة وبما ينيح نمو الثخصية وتطورها.

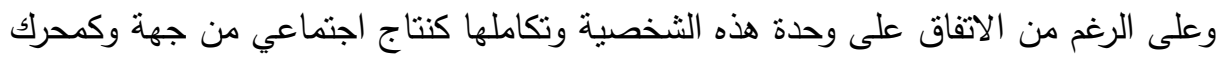

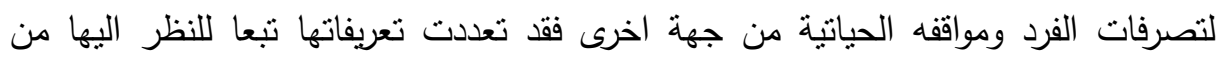
جوانب متعددة. فقد عرفت الثخصية على انها المصطلح الذي يثير الى الفرد والى الطريقة التي يتم بموجبها نتظيم سماته بحيث بدل كل ذللك عليه وعلى نثاطاته كفرد متميز عن غيره وبناءا على ذلك فان اي وصف لشخصية الفرد من الواجب ان يأخذ بالاعتبار مظهره العام وطبيعة قدراته ودوافعه ودور افعاله وطبيعة الخبرات التي سبق ان مر بها ومجموعة القيم

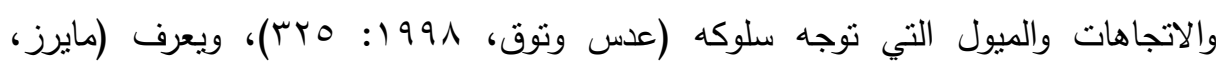

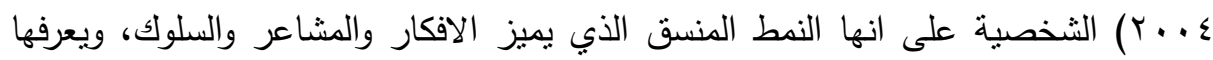

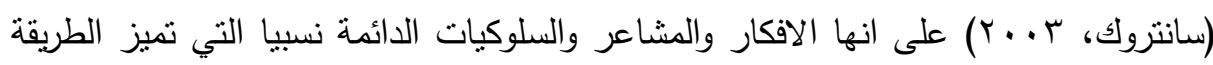


التي يتكيف بها الفرد مع البيئة، وهكذا يمكن القول بان النظرة الحديثة لمفهوم الثخصية نثير

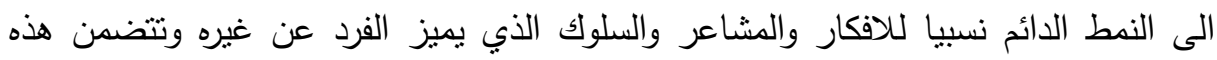

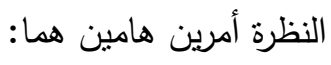
ان لكل فرد نمط خاصا من التفكير والمشاعر والسلوك يميزه عن غيره.

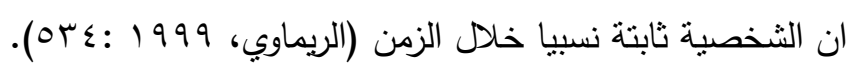

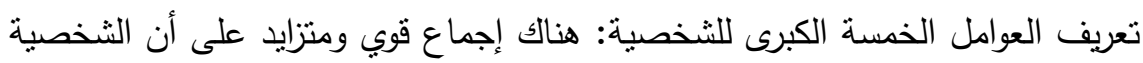
بمكن أن توصف بشكل دقيق من خلال عوامل الشخصية الخمس الرئيسية أو ما بطلق عليه

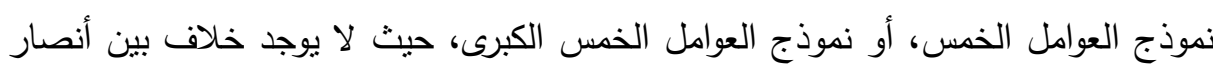

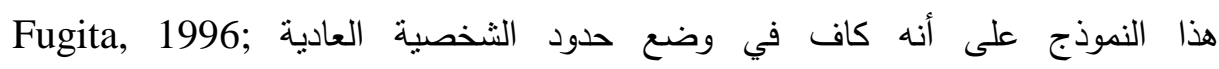
Grandmaison, 2006 الاغتراب: ويعد مفهوم الاغتراب ذا خصوصية مهمة، فهو يعد مؤشراً موثوقاً به لتقييم سياسات معينة خاصة بالتتمية الاقتصادية، والاجتماعية، حتى السياسية، ومفهوم الاغتراب يعكس

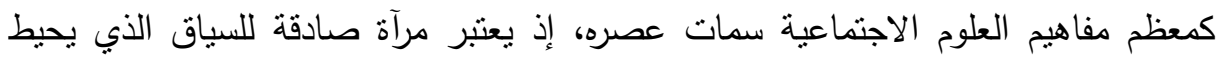

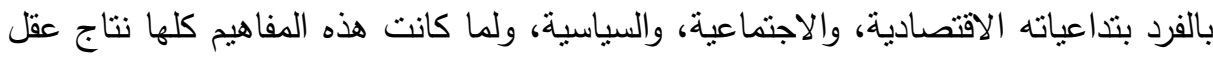
إنساني يعكس الدفكرون سمات عصورهم من خلال مفاهيم تدرس واقعهم وتوصيفه وتقيمه. ويصعب تتاول الاغتراب كمفهوم بعيداً عن الاغتراب كحالة يشعر بها الأفراد، أو حنى بعيداً

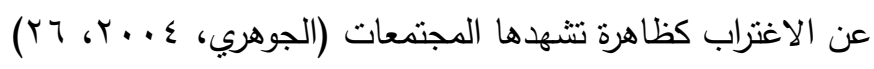

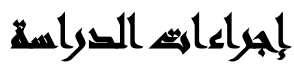

فيما يتعلق بالدراسة الراهنة ومنطلباته، سوف تحاول الباحثة الإفادة من مبدأ المرونة المنهجية باستخدام أكثر من منهج حتى يمكن تحقيق أهداف الدراسة، وللتحقق من فروض لأنس الدراسة الحالية تم استخدام المنهج الوصفي الارتباطي المقارن الذي يقوم على لهن وصف الذف الظاهرة

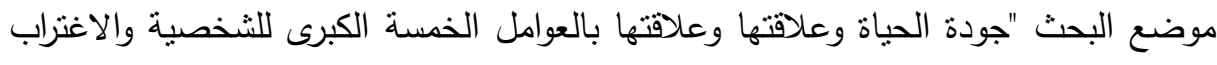
المجتمعي"، ومحاولة إعطاء صورة شبه كاملة عن واقع الظاهرة محل الدراسة، من خلال وعل بله 
الاعتماد على جمع الحقائق ووصفها وتحليلها بهدف الوصول إلى وصف دقيق للظاهرة محل الدراسة من واقع مجتمع الدراسة.

وذلك من خلال المقارنة بين أبناء البيئة الحضرية (العليا، والوسطى، والدنيا) في متغيرات البحث "جودة الحياة بأبعاده الفرعية، وعوامل الثخصية الخمس الكبرى والاغتراب لئه المجتمي"، ومحاولة التتبؤ بالاغتراب المجتمعي من خلال أبعاد متغير جودة الحباة، والعوامل الخمسة الكبرى للثخصية وتحديد درجة إسهامها في تتكيل المتغير التابع "الاغتراب

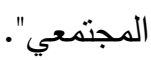

\section{أسواهث التصاسم}

قام الباحثنون بالاطلاع على المقاييس التي تلائم المتغيرات موضع الاهتمام، وكذا طبيعة

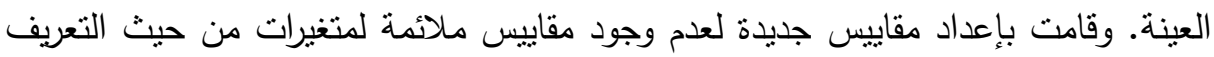

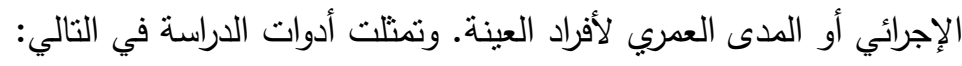
مقياس جودة الحياة (إعداد: الباحثه) يتكون المقياس في صورته النهائية من • 7 مفردة موزعة على أربعة أبعاد أساسية كما يلي. جدول (1): الأربع أبعاد الأساسية لمقياس جودة ابعاد الحياة

\begin{tabular}{|c|c|c|}
\hline العبارات & أبعاد مقياس جودة الحياة & p \\
\hline $10: 1$ & السلامة الجسدية & 1 \\
\hline r.: 17 & الصحة النفسية & r \\
\hline \&0:M & العلاقات الإجتماعية والتواصل مع الآخرين & $r$ \\
\hline $7 \cdot: \leqslant 7$ & إدارة الوقت & $\varepsilon$ \\
\hline
\end{tabular}

وتتم الاستجابة على عبارات المقياس من خلال الاختيار بين عدد من بدائل الاستجابات

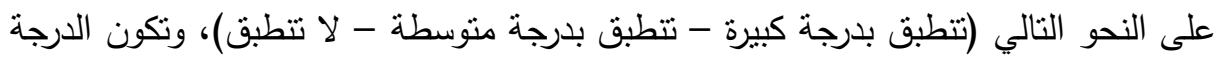

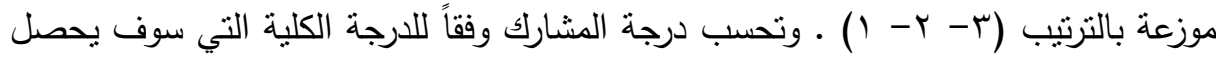
عليها في المقياس ككل، بعد جمع درجات الأبعاد الفرعية للمقياس والدرجة الكلية للمقياس

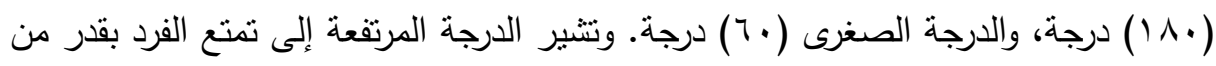

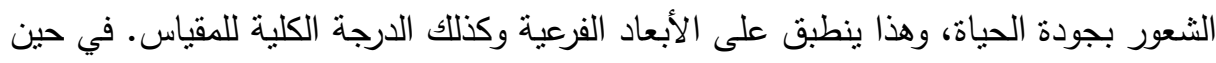


تتير الدرجة المنخفضة إلى عكس ذلك ـ ثم التحقق من الصدق والثبات للمقياس حيث يتم حساب صدق المقياس. • • صدق المحتوى content validity. • • عدق التكوين construct validity

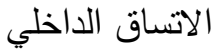

ويتم حساب ثبات المقياس بطريقتن مختلفتين هما: معامل ألفا- كرونباخ: قامت الباحثة بحساب الثبات باستخدام معامل ألفا كرونباخ على عينة

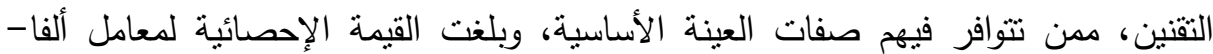
كرونباخ ^9V, · وهو ما يثير إلى أن معامل الثبات يعد معامل مرتفع إلى حد كبير ، ويوضح أن المقياس يتمتع بدرجة كبيرة من الثبات. طريقة القسمة النصفية: وفيه تم تقسيم الاختبار إلى جزئين: الأول للبنود الفردية، والآخر للبنود الزوجية (طريقة الفردي - زوجي). وقد أظهر المقياس معامل ارتباط مرتفع بدرجة كبيرة، بلغت الته قيمته V \& \&, · ويتضح أن معامل الثبات يعد معامل مرتفع إلى حد كبير ، ويوضح أن المقياس يتمتع بدرجة كبيرة من الثبات

$$
\text { مقياس قائمة العوامل الخمسة الكبرى للشخصية (إعداد: كوستا وماكري) }
$$

يتكون المقياس في صورته النهائية من ـ مفردة موزعة على أربعة أبعاد أساسية هي:

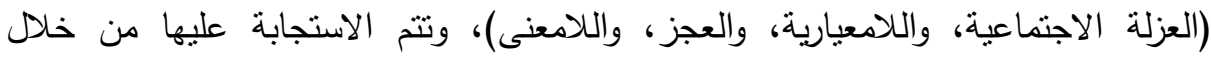

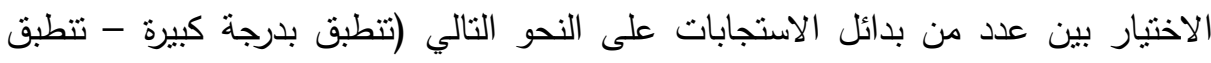

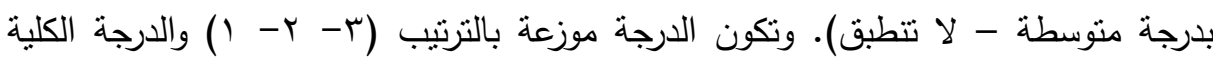

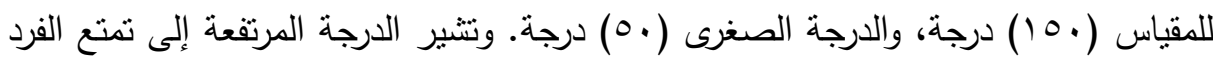

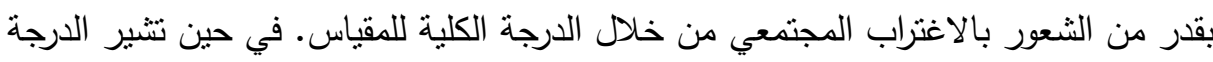
المنخفضة إلى عكس ذلك. 


$$
\begin{aligned}
& \text { تم حساب صدق المقياس عن طريق: } \\
& \text { صدق المحتوى content validity. } \\
& \text { صدق النكوين construct validity } \\
& \text { الاتساق الداخلي. } \\
& \text { ويتم حساب الثبات بطريقتين: }
\end{aligned}
$$

- حساب معامل ألفا - كرونباخ: قامت الباحثة بحساب الثبات باستخدام معامل ألفا

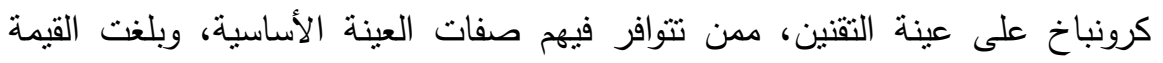

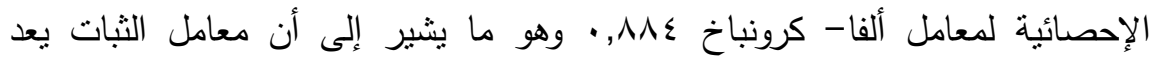
معامل مرتفع إلى حد كبير ، ويوضح أن المقياس يتمتع بدرجة كبيرة من الثبات.

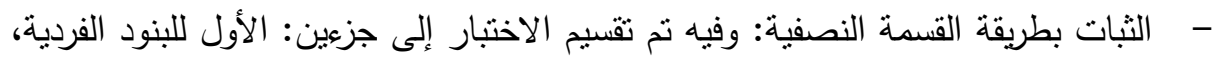

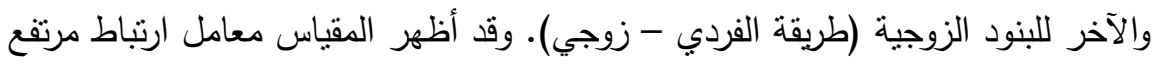

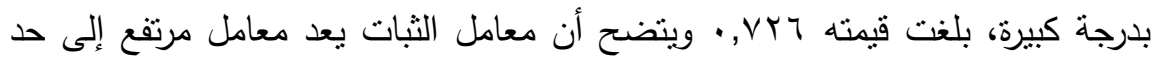

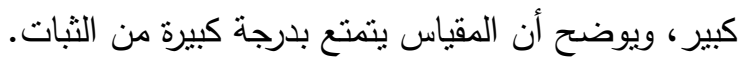

\section{Dang}

المجال البشرى: تم تطبيق أدوات البحث على افراد البيئة الحضرية فى محافظة المنيا وفق مستوى جودة الحياة فيها مع اختلاف البناء الثقافى الذى يحكم الحياه الاجتماعية فيها وفقاً للبيئات الثلاثة المكونة للبيئة الحضرية وهى البيئة الحضرية العليا والبيئة الحضرية الوسطى البئي والبيئة الحضرية الدنيا. المجال الجغرافي: تم إجراء البحتفى محافظة المنيا وهى واحدة من محافظات صعيد مصر وتم اختيار العينة على اساس الموقع الجغرافى داخل المحافظة الذى يحدد بيئات المجتمع وهئ الثلاثة وهى البيئة العليا والوسطى والدنيا وتكون كالتالي: التياني: • البيئة الحضرية العليا، وتمنلها:(منطقة ابراج الجامعة، ومنطقة شلبئه، ونكي، ومنطقة ارض سلطان). 
البيئة الحضرية الوسطى، وتمنلها: (منطقة وسط المدنية، شارع الحسينى، وشارع ابن خصيب، وشارع التجارة).

البيئة الحضرية الدنيا، وتمنلها: (منطقة ابو هلاد وأرض المولد والعزبة).

\section{xang}

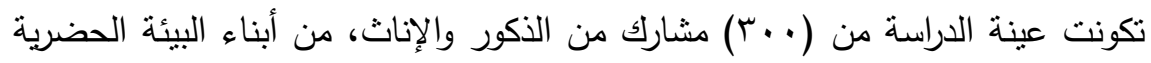

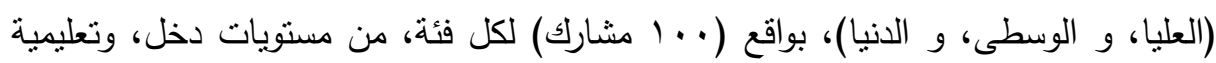

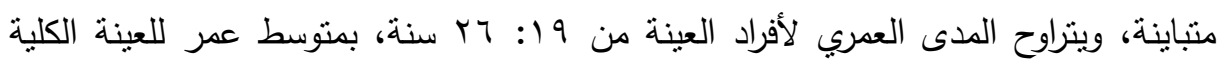

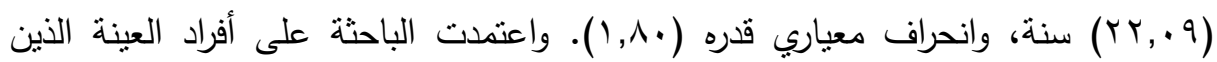

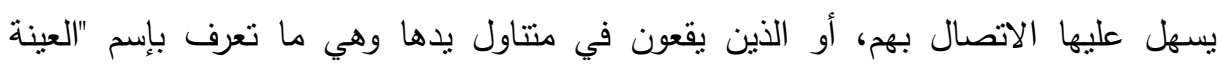

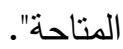

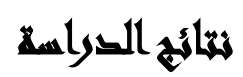

فيما يتعلق بالفرض الأول والذي يشير إلى "وجود فروق بين أفراد عينة البحث من أبناء

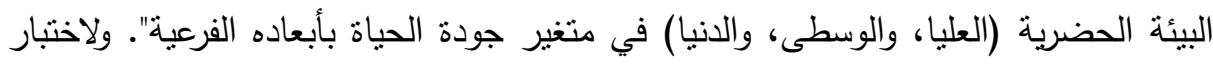

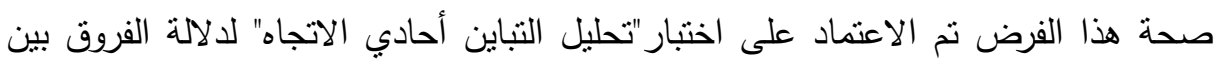

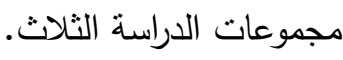


ايناس فاروق التلاوي وآخرون

جدول (r): يوضح الإحصاءات الوصفية لمجوعات البحث

\begin{tabular}{|c|c|c|c|c|}
\hline المعياري & الحسابي & العدد الع & مجموعات البحث & المتغيرات \\
\hline $0, \cdot 7$ & $r V, r \wedge$ & $1 \ldots$ & البيئة الحضرية العليا & \multirow{4}{*}{ السلامة الجسدية } \\
\hline 0,11 & YT,IV & $1 \ldots$ & البيئة الحضرية الوسطى & \\
\hline $1, \leqslant 9$ & $i v, \ldots$ & $1 \ldots$ & البيئة الحضرية الدنيا & \\
\hline $9,7 \varepsilon$ & $r 0,01$ & r... & المجموع & \\
\hline$\varepsilon, 1 q$ & $r v, v T$ & $1 \ldots$ & البيئة الحضرية العليا & \multirow{4}{*}{ الصحة النفسية } \\
\hline$r, 19$ & ro, $1 \wedge$ & $1 \ldots$ & البيئة الحضرية الوسطى & \\
\hline$r, r \wedge$ & $11, \cdot 7$ & $1 \ldots$ & البيئة الحضرية الدنبا & \\
\hline$\Lambda, \wedge r$ & $r v, \ldots$ & $r \ldots$ & المجموع & \\
\hline $0,1 \pi$ & $r v, \cdot r$ & $1 \ldots$ & البيئة الحضرية العليا & \multirow{4}{*}{ والتواصل مع الآخرين } \\
\hline 7,1 & $r 7, \cdot 1$ & $1 \ldots$ & البيئة الحضرية الوسطى & \\
\hline$r, \vee q$ & $19, \mathrm{YV}$ & $1 \ldots$ & البيئة الحضرية الدنيا & \\
\hline$\Lambda, 9 Y$ & $r V, \varepsilon r$ & $r \ldots$ & المجموع & \\
\hline $0, Y 7$ & $r V, I T$ & $1 \ldots$ & البيئة الحضرية العليا & \multirow{4}{*}{ إدارة الوقت } \\
\hline$r, 70$ & $r_{0, \varepsilon} \leqslant$ & $1 \ldots$ & البيئة الحضرية الوسطى & \\
\hline$Y, Y V$ & IV, ro & $1 \ldots$ & البيئة الحضرية الدنبا & \\
\hline $9, \cdot r$ & rצ,ד & $r \ldots$ & المجموع & \\
\hline $\mid r, 91$ & $1 \leq 9, \times 9$ & $1 \ldots$ & البيئة الحضرية العليا & \multirow{4}{*}{ الدرجة الكلية لمتغير جودة } \\
\hline 9,94 & $9 \wedge, \vee 9$ & $1 \ldots$ & البيئة الحضرية الوسطى & \\
\hline $7, \varepsilon \wedge$ & $\vee 1,7 \wedge$ & $1 \ldots$ & البيئة الحضرية الدنيا & \\
\hline$r \mu, \wedge \Lambda$ & $1.7,01$ & $r \ldots$ & المجموع & \\
\hline
\end{tabular}


مجلة العلوم البيئية

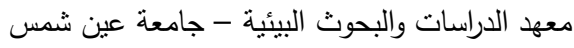

جلول (ץ): تحليل التباين في اتجاهواحد بين المجموعات الثلاثة من أبناء البيئة الحضرية في

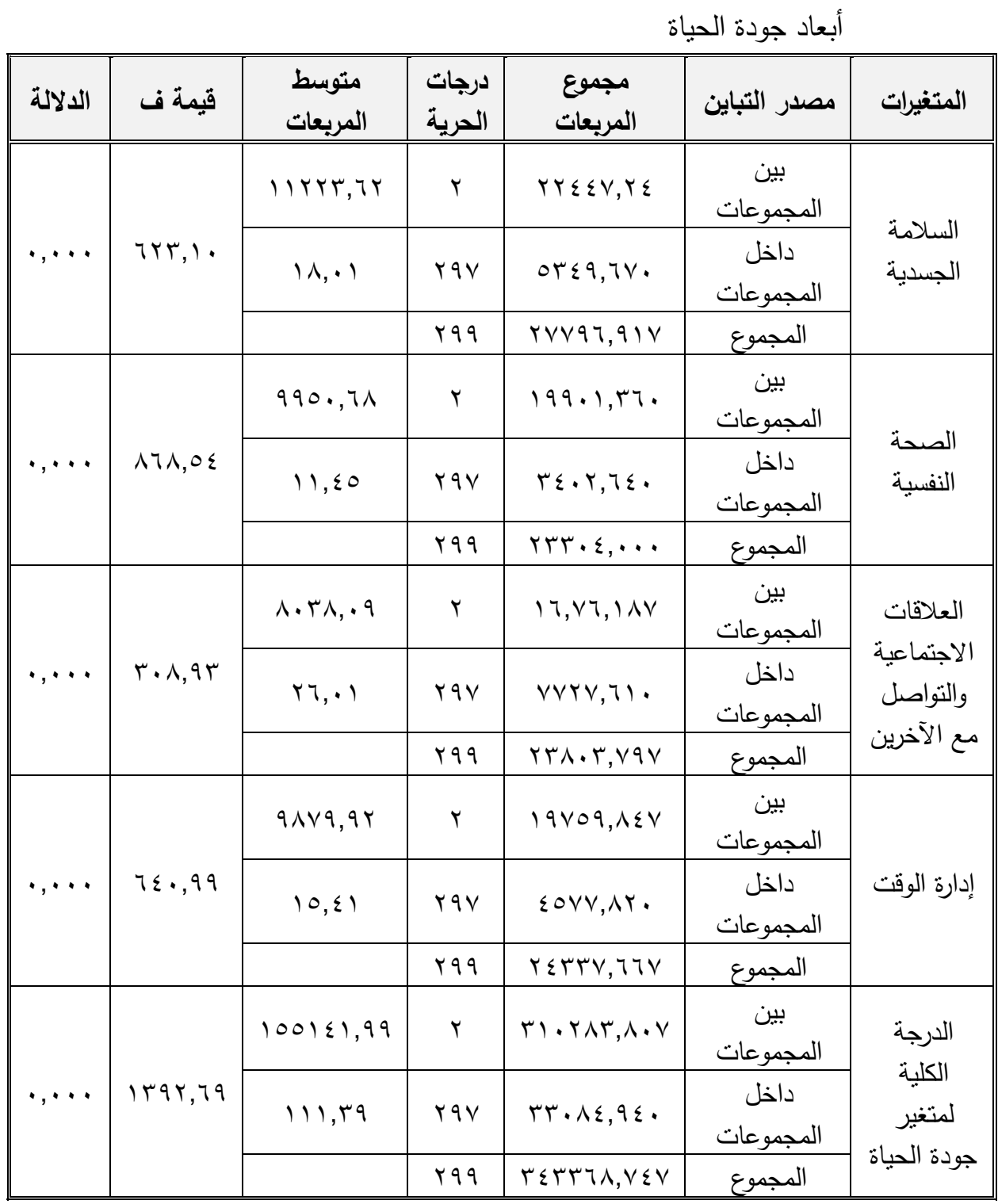

المجلد السابع والأربعون، الجزء الثالث، سبتمبر 9 ( ـ ب 
يتضح من الجدول السابق وجود فروق دالة إحصائيًا بين المجموعات الثناث (أبناء

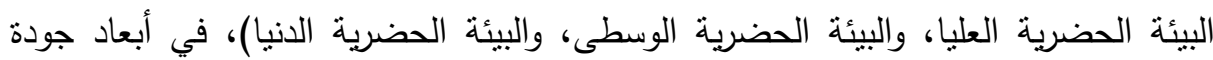
الحياة (السلامة الجسدية، والصحة النفسية، والعلاقات الاجتماعية والتواصل مع الآخرين، ولهنه

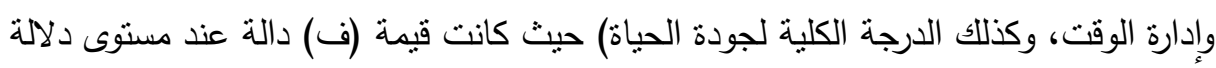

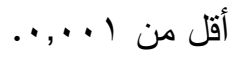

وجود فروق بين أفراد عينة الدراسة من أبناء البيئة الحضرية (العليا، والوسطى، والدنيا)

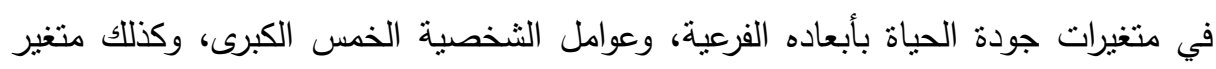
الاغتراب المجتمي. إضافة إلى وجود فروق في متغيرات الدراسة يمكن أن تعزي إلى نأثثران النوع، ومستوى الدخل، والمستوى التعليمي، لدى أفراد العينة الكلية. وقد كثفت نتائج الدراسة عن وجود فروق في جودة الحياة وأبعادها الفرعية (السلامة

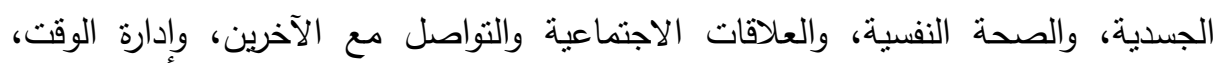

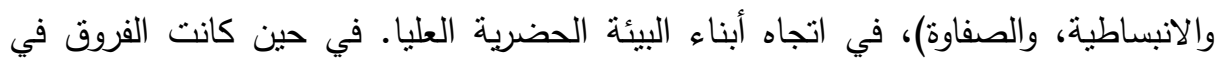

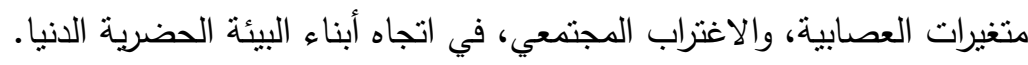

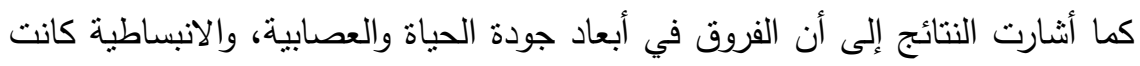

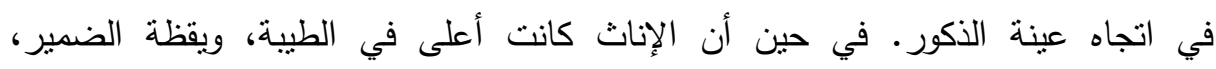
والاغتراب المجتمعي. وعدم وجود فروق في (العلاقات الاجتماعية والتواصل مع الآخرين،

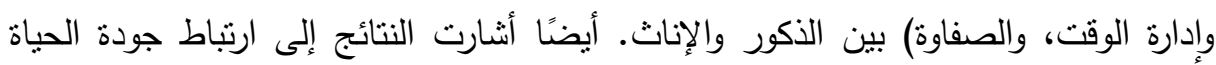

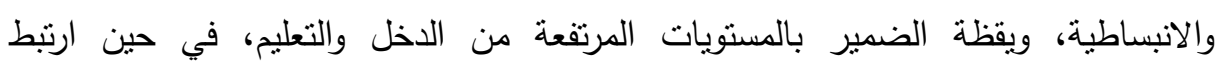
الاغتراب المجتمعي بالمستويات الأقل منها.

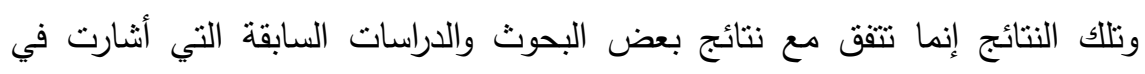
مضمونها إلى ارتباط جودة الحياة بالرفاهية النفسية والثعور بالصحة النفسية السوية وارتباطها

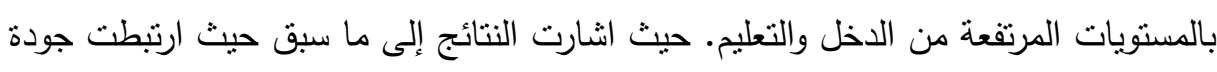

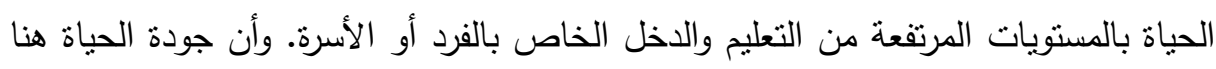

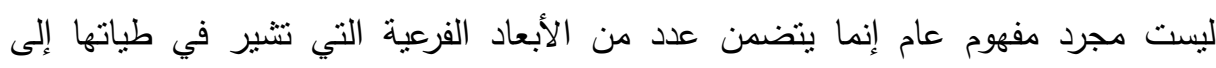
مختلف الجوانب الحياتية والمهارات الثخصية للفرد؛ مثل (السلامة الجسدية، والصحة النفسية، 
والعلاقات الاجتماعية والتواصل مع الآخرين، وإدارة الوقت)، ومن هنا نسنطيع أن نقول أن

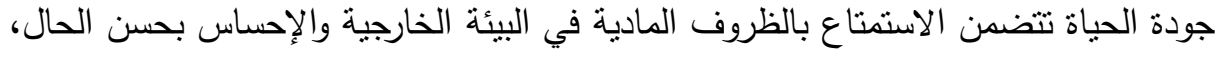

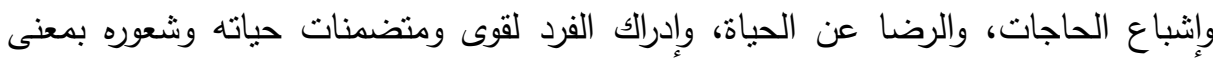
الحياة، إلى جانب الصحة الجسمية الإيجابية، وإحساسه بمعنى السعادة وصولا إلى العيش ولى ولى

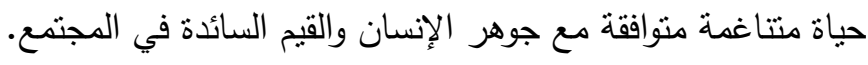

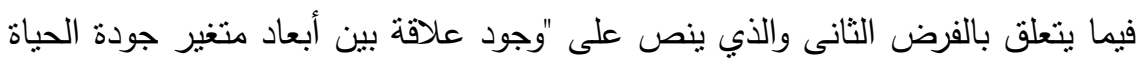

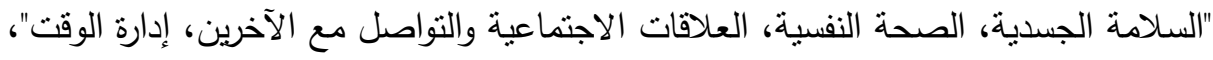
ومتغير الاغتراب المجتمعي، كما أنها تعد ذات قدرة تتبؤية عالية بالاغتراب، لدى أفراد العينة

جدول ( ) ): يوضح نتائج المقارنات المتعددة

\begin{tabular}{|c|c|c|c|}
\hline P.Value & متوسط الفرق & المقارنات الثنائية & 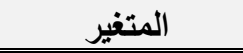 \\
\hline$\cdot, \cdots$ & $10, Y^{\prime \prime}$ & البيئة الحضرية العليا/ البيئة الحضرية الوسطى & \multirow{3}{*}{ السلامة الجسدية } \\
\hline$\cdot, \ldots$ & $r \cdot, r \Lambda^{*}$ & البيئة الحضرية العليا/ البيئة الحضرية الدنيا & \\
\hline$\cdot, \cdots$ & $0,1 v^{*}$ & البيئة الحضرية الوسطى/ البيئة الحضرية الدنيا & \\
\hline$\cdot, \cdots$ & $\mid r, O \Lambda^{*}$ & البيئة الحضرية العليا/ البيئة الحضرية الوسطى & \multirow{3}{*}{ الصحة النفسية } \\
\hline$\cdot, \ldots$ & $19,7 \cdot *$ & البيئة الحضرية العليا/ البيئة الحضرية الدنيا & \\
\hline$\cdot, \cdots$ & $v, 1 r^{*}$ & البيئة الحضرية الوسطى/ البيئة الحضرية الدنيا & \\
\hline$\cdot, \cdots$ & $11, \cdot r^{*}$ & البيئة الحضرية العليا/ البيئة الحضرية الوسطى & \multirow{3}{*}{ التعلاقات الاجتماعية مع الآخرين } \\
\hline$\cdot, \ldots$ & $I V, V 7^{*}$ & البيئة الحضرية العليا/ البيئة الحضرية الدنيا & \\
\hline$\cdot, \ldots$ & $7, \vee \varepsilon^{*}$ & البيئة الحضرية الوسطى/ البيئة الحضرية الدنيا & \\
\hline$\cdot, \cdots$ & $11,79^{\prime \prime}$ & البيئة الحضرية العليا/ البيئة الحضرية الوسطى & \multirow{3}{*}{ إدارة الوقت } \\
\hline$\cdot, \cdots$ & $19, V V^{*}$ & البيئة الحضرية العليا/ البيئة الحضرية الدنيا & \\
\hline$\cdot, \cdots$ & $\Lambda, \cdot \Lambda^{*}$ & البيئة الحضرية الوسطى/ البيئة الحضرية الدنيا & \\
\hline$\cdot, \cdots$ & $0 ., 0 . *$ & البيئة الحضرية العليا/ البيئة الحضرية الوسطى & \multirow{3}{*}{ لمتغير جودة الدرجة الكلية } \\
\hline$\cdot, \cdots$ & $V V, T)^{*}$ & البيئة الحضرية العليا/ البيئة الحضرية الدنبا & \\
\hline$\cdot, \cdots$ & $r v, 11^{\prime \prime}$ & البيئة الحضرية الوسطى/ البيئة الحضرية الدنيا & \\
\hline
\end{tabular}


ويشير الجدول السابق إلى التالي:

فيما يتعلق السلامة الجسدية، يتضح أن هناك اختلافًا معنويًا بين المجموعات الثناث،

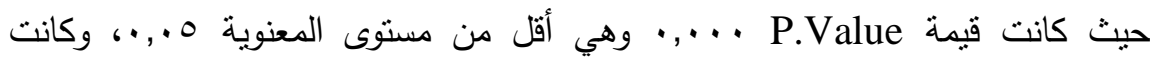
الفروق في اتجاه أبناء البيئة الحضرية العليا؛ حيث بلغت قيمة المتوسط الحسابي لها لها

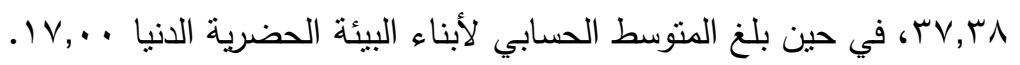

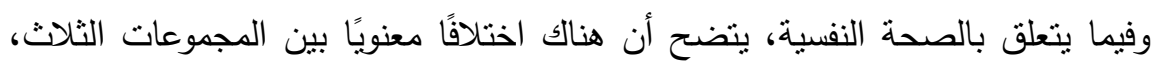

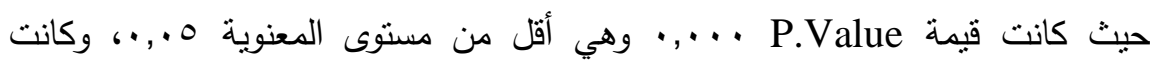
الفروق في اتجاه أبناء البيئة الحضرية العليا؛ حيث بلغت قيمة المتوسط الحسابي لها لها لهاء

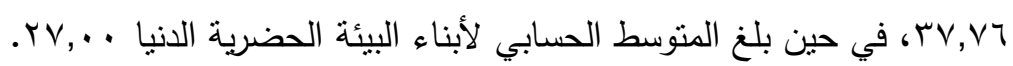

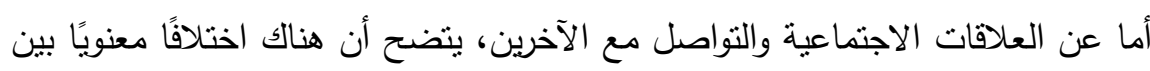

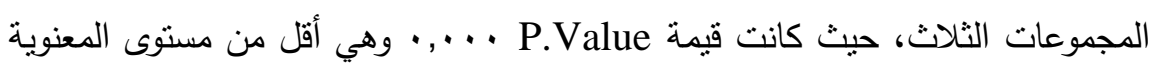

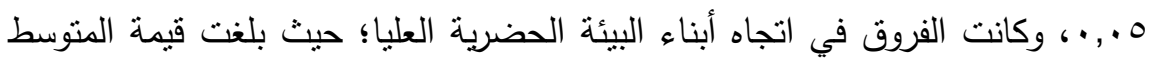

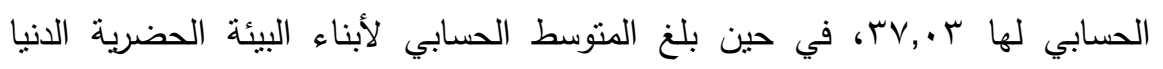
. YV, \&

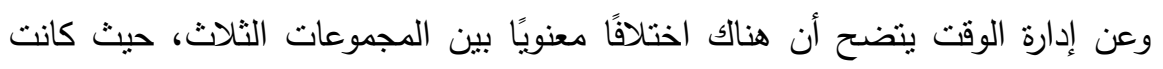

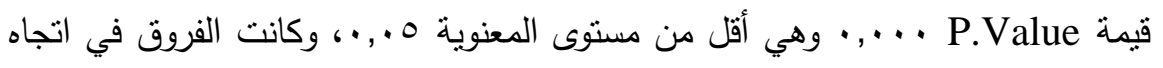

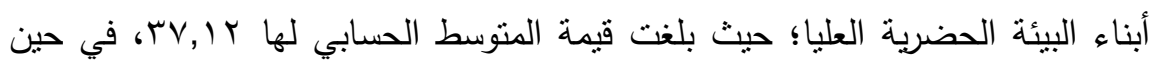

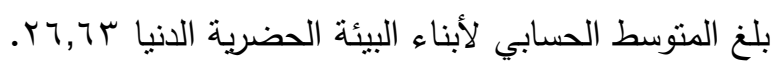

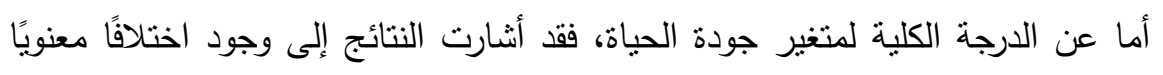

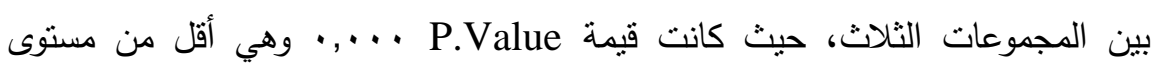

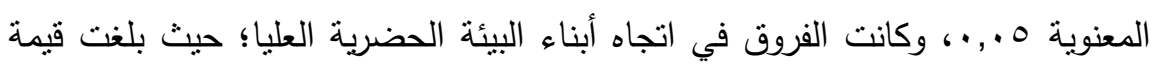

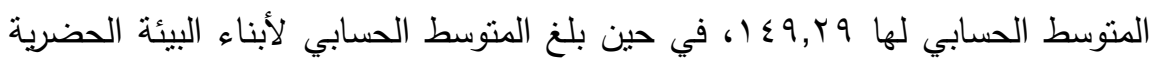
الانيا ويفهم مما سبق أن الفروق في درجات جودة الحياة وأبعادها الفرعية (السلامة الجسدية،

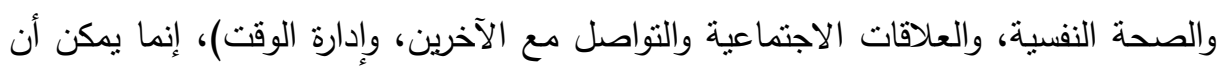


نعزوها إلى طبيعة البيئة التي ينشأ فيها الفرد ؛حيث ارتبطت الفروق بالمستويات المرتفعة من

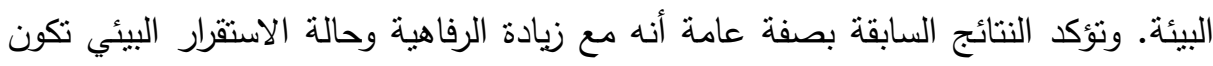

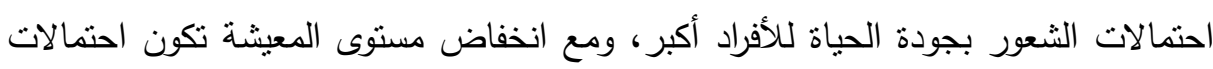
الثعور بجودة الحياة للأفراد أقل. وتؤكد نتائج تحليل التباين السابقة صحة الفرض التفرئ المطروح. وقد كثفت نتائج الدراسة عن وجود علاقة عكسية قوية بين الاغتراب المجتمي وجميع

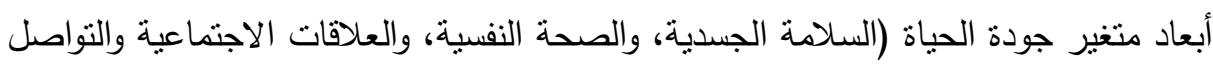

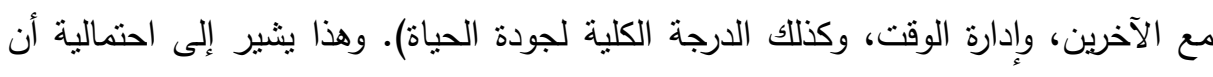
تزداد معدلات الشعور بالاغتراب المجتمي مع انخفاض جودة الحياة، والعكس صحيح.

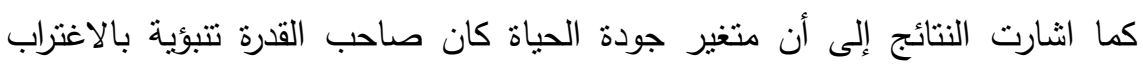

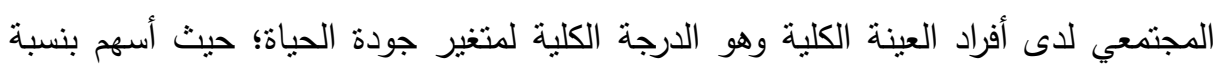

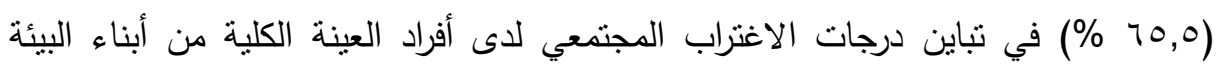

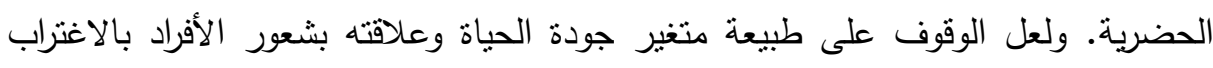

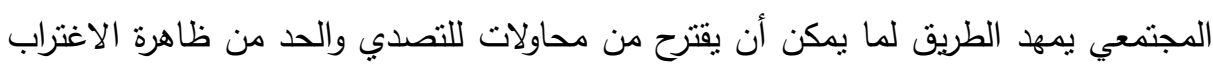
وما قد ينجم عنها من سلوكيات منطرفة تتسم بالعنف، والعمل على تقليل أخطارها وآثارها

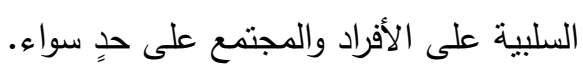

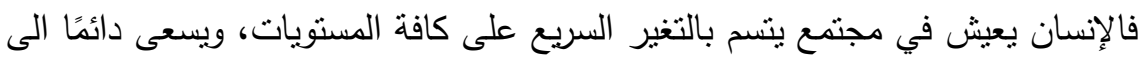

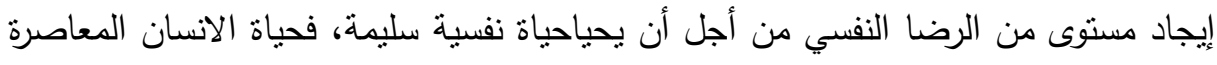

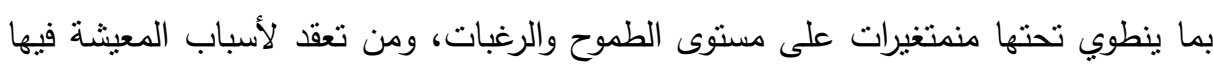

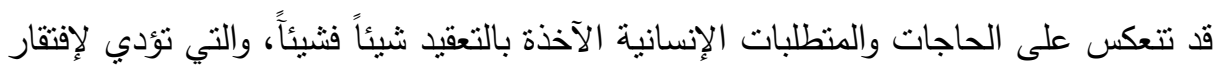
الإنسان الى حالة الاستقرار النفسي والذي ينعكس سلباً على شعوره بالأمان والاطمينّان.

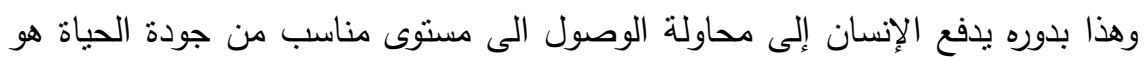

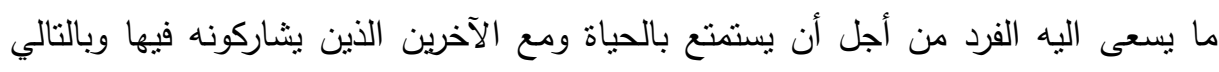

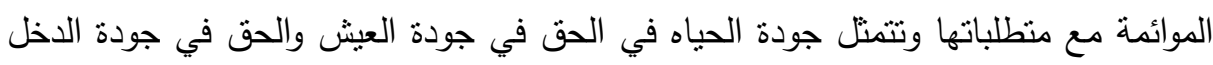


والحق في جودة الصحة والحق في جودة المشاركة السياسية، والحق في جودة الثقافة والحق في جودة الامن والحق في جودة البيئة. وفي ضوء ذللك يمكنا القول بأن لجوء الأفراد للسلوك المنحرف إنما قد ينجم عن شعوره

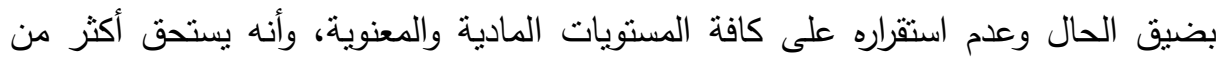
وضعه الراهن بكثير وأن المجتمع لا يقدر قدراته وامكاناته. فذلك الفرد يكون بمثابة فريسة وانه

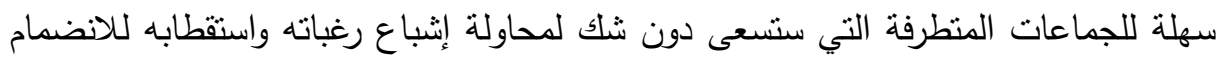
اليها، وهنا قد يتوحد ذللك الفرد مع تللك الجماعات فيؤمن بأفكارها ومعتقداتها ويدافع عنها بل دئل دئل

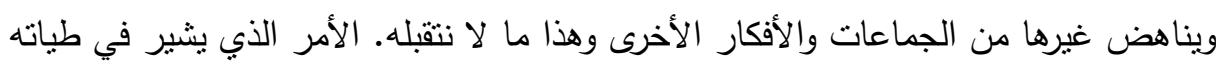

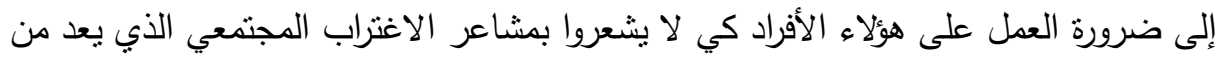

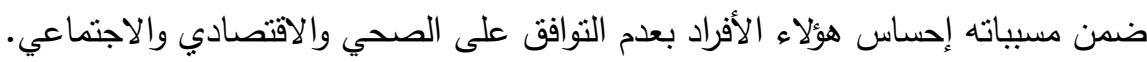

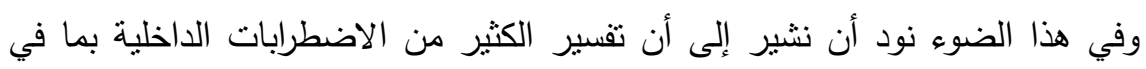

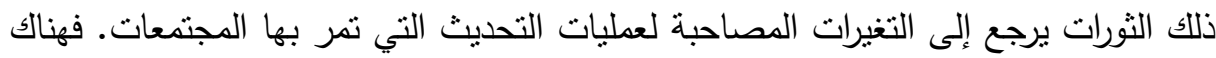

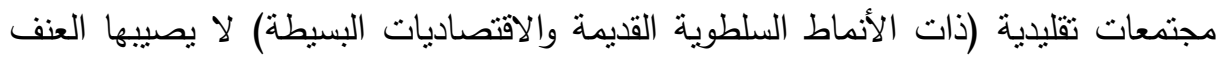

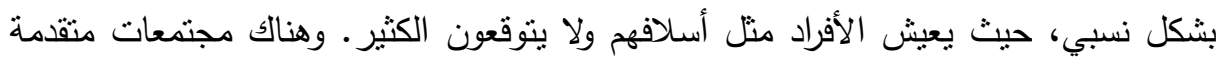

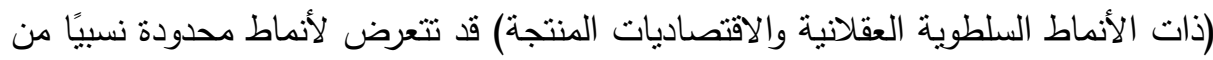

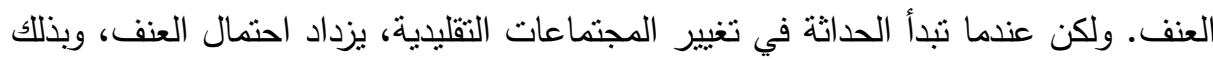
تكون قد خرجت من مرحلة الاستقرار التقليدي، ولكنها لم تصل بعد لمرحلة الاستقرار

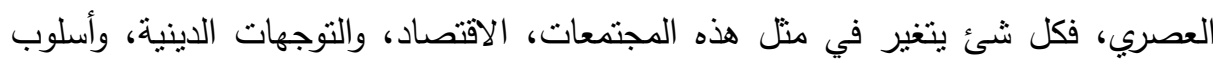

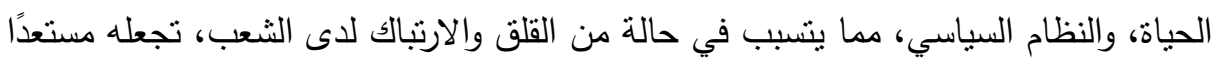

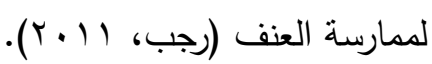

وفيما يتعلق بالفرض الثالث والذي يشير إلى "وجود فروق بين أفراد عينة الدراسة من أبناء البيئة الحضرية (العليا، والوسطى، والدنيا) في العوامل الخمسة الكبرى للشخصية".

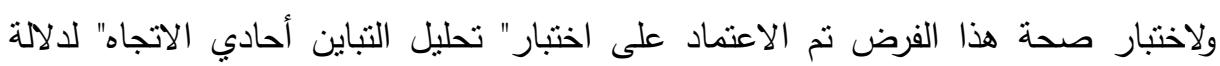
الفروق بين مجموعات البحث الثلاثة. 
مجلة العلوم البيئية

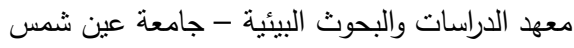

جدول (ه): الإحصاءات الوصفية لمجوعات البحث

\begin{tabular}{|c|c|c|c|c|}
\hline الانحراف المعياري & المتوسط الحسابي & العدد & مجموعات البحث & المتغيرات \\
\hline $1,1,1 \leq r 7 q$ & $r q, q \leqslant 0$ & $1 \ldots$ & البيئة الحضرية العليا & \multirow{4}{*}{ العصابية } \\
\hline$M, N \mid r V T$ & $r v, T \leq$ & $1 \ldots$ & البيئة الحضرية الوسطى & \\
\hline 11,11090 & $\{r, r\}$ & $1 \ldots$ & البيئة الحضرية الدنبا & \\
\hline$M, \cdot r T \leq r$ & $\varepsilon \cdot, \leqslant 0$ & r.. & المجموع & \\
\hline דוזה.0,0 & $V Y, T$ & $1 \ldots$ & البيئة الحضرية العليا & \multirow{4}{*}{ الانبساطية } \\
\hline $1 V, r q .7 r$ & $T \vee, \vee \wedge$ & $1 \ldots$ & البيئة الحضرية الوسطى & \\
\hline 1N,OYY $\leq \varepsilon$ & $7 \varepsilon, 9$ & $1 \ldots$ & البيئة الحضرية الدنيا & \\
\hline $17, \mathrm{VAOVV}$ & T9,1 r & r... & المجموع & \\
\hline $19, \Lambda \cdot Y Y_{0}$ & $11 \leqslant, 97$ & $1 \ldots$ & البيئة الحضرية العليا & \multirow{4}{*}{ الصفاوة } \\
\hline$r \neg, r \leq \wedge \wedge r$ & $1 \cdot V, V Y 0$ & $1 \ldots$ & البيئة الحضرية الوسطى & \\
\hline$r \wedge, \ldots 197$ & $1 \cdot r, 0 \leq$ & $1 \ldots$ & البيئة الحضرية الدنيا & \\
\hline rE,VTrII & $1.9,01 Y$ & $r \ldots$ & المجموع & \\
\hline IY,YOT $\leqslant V$ & $r q, \vee \leqslant 0$ & $1 \ldots$ & البيئة الحضرية العليا & \multirow{4}{*}{ الطيية } \\
\hline 11, rVAтr & $\varepsilon Y, V Y \vee \wedge$ & $1 \ldots$ & البيئة الحضرية الوسطى & \\
\hline$M, Y \Lambda .90$ & $r \wedge, r \cdot \Lambda r$ & $1 \ldots$ & البيئة الحضرية الدنيا & \\
\hline $1 Y, \cdot T 7 \leqslant r$ & $\varepsilon \cdot, \leqslant 0$ & $r \ldots$ & المجموع & \\
\hline$|V, \Gamma \wedge| 9 \wedge$ & $T V, Y \leq$ & $1 \ldots$ & البيئة الحضرية العليا & \multirow{4}{*}{ يقظة الضمير } \\
\hline $1 \leq, V \leq r \leq 9$ & VT,TVYY & $1 \ldots$ & البيئة الحضرية الوسطى & \\
\hline IV,\&AOVT & $70,9 Y_{0}$ & $1 \ldots$ & البيئة الحضرية الدنيا & \\
\hline $17, \mathrm{VAOVV}$ & T9,1 r & $r \ldots$ & المجموع & \\
\hline
\end{tabular}


جدول (†): تحليل التباين في اتجاه واحد بين المجموعات الثناثة من أبناء البيئة الحضرية في

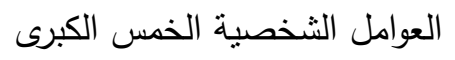

\begin{tabular}{|c|c|c|c|c|c|c|}
\hline الدلالة & قيمة & المربعات & الحرية & مجموع المريعات & مصدر التباين & المتغيرات \\
\hline \multirow{3}{*}{$\cdot, \cdots \varepsilon$} & \multirow{3}{*}{$0, \varepsilon \wedge q$} & $\mathrm{~V} \wedge 0,11 \mathrm{~V}$ & $r$ & 10V•,rTo & بين المجموعات & \multirow{3}{*}{ العصابية } \\
\hline & & $1 \leq r, \cdot r_{0}$ & YqV & VI. Nr,or & داخل المجموعات & \\
\hline & & & $r 99$ & VYYor,Vo & المجموع & \\
\hline \multirow{3}{*}{$\cdot, \cdots$} & \multirow{3}{*}{ אחזr, } & 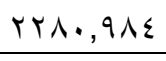 & $r$ & 5071,971 & بين المجموعات & \multirow{3}{*}{ الانبساطية } \\
\hline & & rVT,VIV & Y१V & r r & داخل المجموعات & \\
\hline & & & r99 & $1 \varepsilon .099, r$ & المجموع & \\
\hline \multirow{3}{*}{$\cdot, \cdots$} & \multirow{3}{*}{$9,7 V$} & OVIT,TYI & r & $11 \leq r r, Y \leq$ & بين المجموعات & \multirow{3}{*}{ الصفاوة } \\
\hline & & $091,1 \wedge \varepsilon$ & YQV & 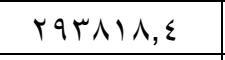 & داخل المجموعات & \\
\hline & & & r99 & $r .0 Y 01,7$ & المجموع & \\
\hline \multirow{3}{*}{$\cdot, \cdot r$} & \multirow{3}{*}{$0, Y Y T$} & 111,101 & $r$ & ITr,r.r.r & بين المجموعات & \multirow{3}{*}{ الطيبة } \\
\hline & & $1 \leq r, \wedge 9 r$ & rqV & $V 1 \cdot 1 V, \varepsilon 0$ & داخل المجموعات & \\
\hline & & & $r 99$ & VYTOY,VO & المجموع & \\
\hline \multirow{3}{*}{$\cdot, \cdots$} & \multirow{3}{*}{9,011} & Y०9r,YII & $r$ & $01 \wedge T, \Sigma Y Y$ & بين المجموعات & \multirow{3}{*}{ الضنة } \\
\hline & & YVY, $\Sigma T$ & Y9V & $1 r 0 \leqslant 1 r, q$ & داخل المجموعات & \\
\hline & & & rq9 & $1 \varepsilon .099, r$ & المجموع & \\
\hline
\end{tabular}

يتضح من الجدول السابق وجود فروق دالة إحصائيًا بين المجموعات الثناث (أبناء البيئة الحضرية العليا، والبيئة الحضرية الوسطى، والبيئة الحضرية الدنيا)، في العوامل الثخصية الخمس الكبرى، حيث كانت قيمة (ف) دالة عند مستوى دلالة أقل من ال . .,...

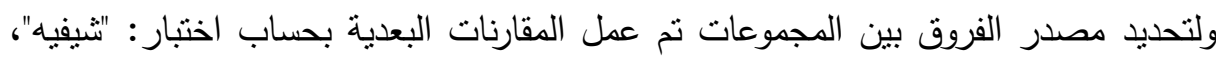

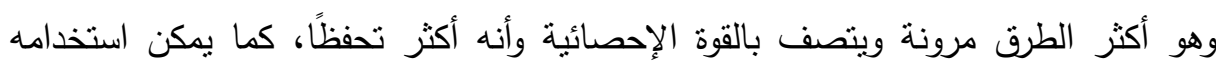

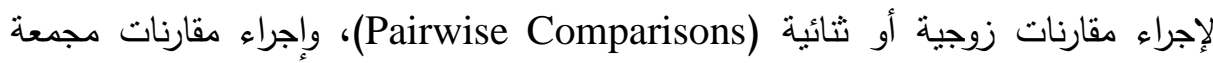
(Compound Comparisons)؛ بالإضافة إلى ذلك يستخدم هذا الاختبار في حالة العينات

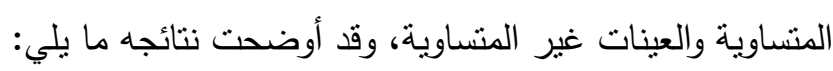
• وجود فروق في متغير العصابية في اتجاه أبناء البيئة الحضرية الدنيا. • وجود فروق في متغيري الانبساطية والصفاوة في اتجاه أبناء البيئة الحضرية العليا. 
وجود فروق في متغيري الطيبة ويقظة الضمير في اتجاه أبناء البيئة الحضرية الوسط.

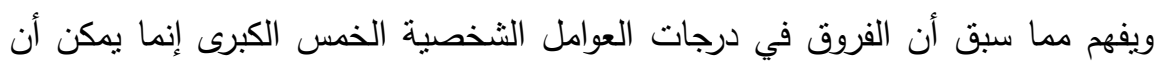

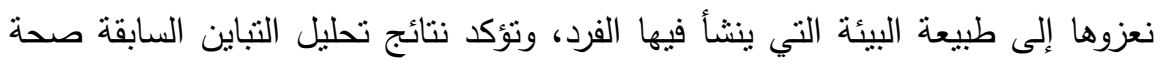

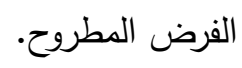

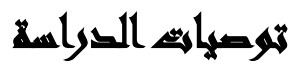

تقاس جودة العمل البحثي بمقدار ما يثيره من أسئلة بحثنة مستقبلية، يمكن إنجازها

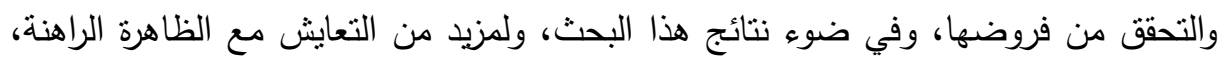

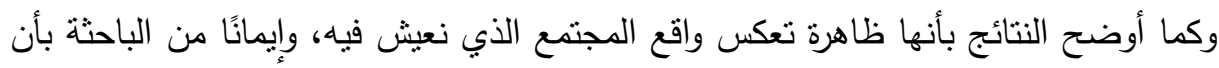

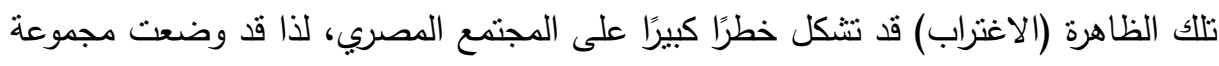

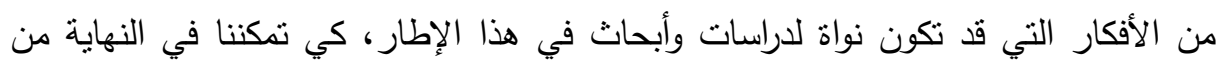
وضع إطار نظري منكامل لظاهرة الاغتراب على وجه التحديد، ويمكن أن تتمثل نتلك الأفكار فيما بلي: الاهنمام بدراسة الفئات المهشة، ودراسة الهامشية الاجتماعية باعتبارها إطار لتفسير

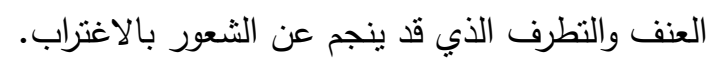

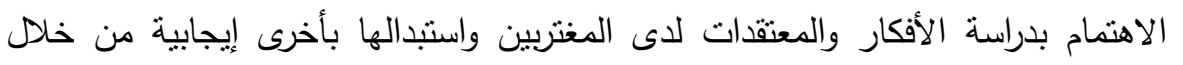

الاهتمام بدراسة الثرائح المختلفة من المجتمع المصري؛ لأن البحث الحالي ركز على بلى

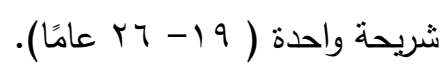

• الاهتمام بدراسة دور مؤسسات التتشئة الاجتماعية والأسرة والمؤسسات التعليمية، وجماعات

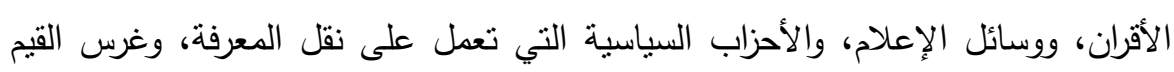

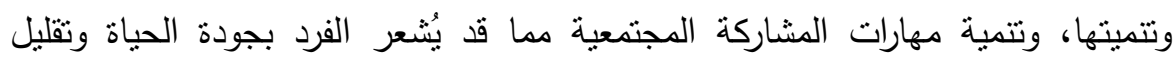


دراسة نأثثر المعالجة الإعلامية للقضايا الاجتماعية والسياسية المطروحة على الساحة ودورها في تشكيل معتقدات الأفراد واتجاهاتهم وسلوكياتهم.

• العمل على تتمية الوعي بمختلف الطرق كي نتمكن من التصدي للظواهر السلبية بالمجتمع. • الاهتمام بتصميم برامج إرشادية لتخفيض مستوى الثعور بالاغتراب من خلال البرامج

\section{المرالئ2}

أحمد عبد الخالق (1997) (الصيغة العربية لمقياس نوعية الحياة الصادر عن منظمة الصحة العالمية: نتائج أولية. القاهرة: دراسات نفسية.

rov

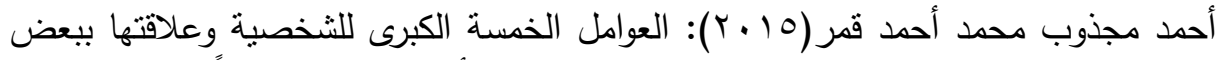

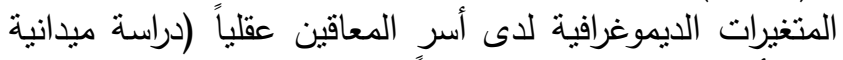
على أسر التلاميذ المعاقين عقلياً بمعهد المستقبل عطبرة). مجلة الدئة

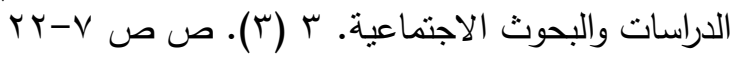

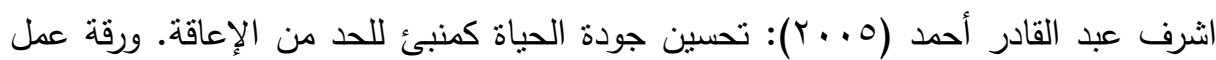
مقدمة لنطوير الأداء في مجال الإعاقة. مكتب التباة التربية العربي

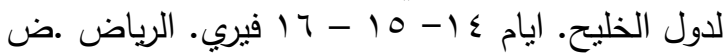

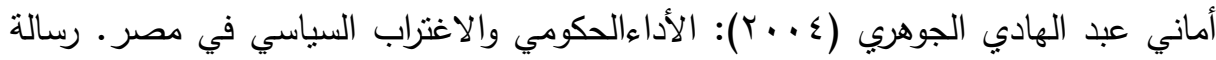

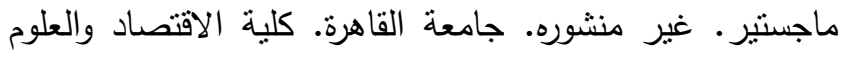

$$
\text { السياسية. }
$$

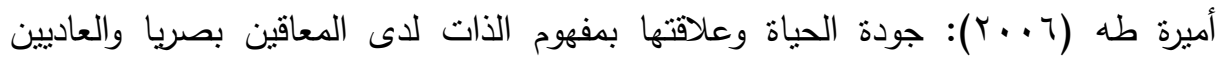
بالمملكة العربية السعودية. جامعة طنطا. كلية التربية. مجلة

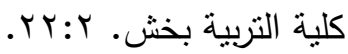

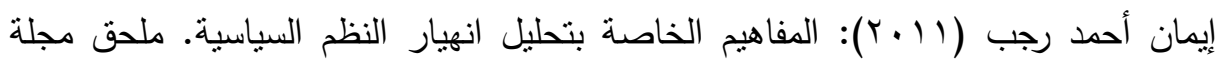
السياسة الدولية - اتجاهات نظرية في تحليل السياسة الدولية،

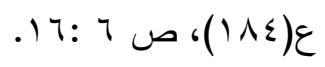




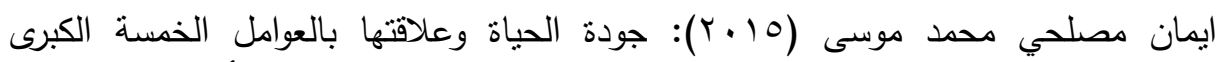

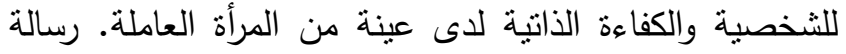

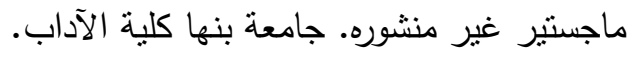

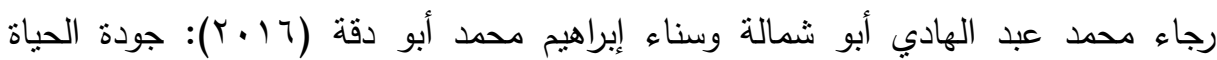

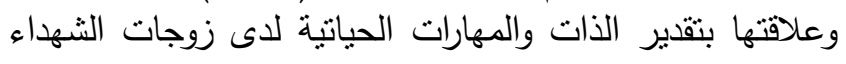
في قطاع غزة. الجامعة الإسلامية. كلية التربية - غزة.

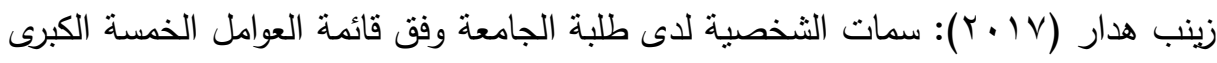

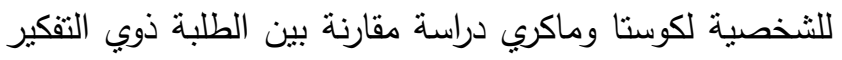
الإيجابي وذوبي التفكير السلبي بجامعة درائة غرداية.

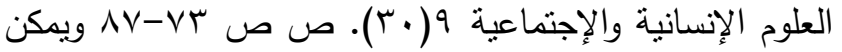
خلا

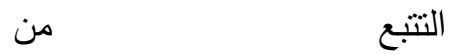
https://www.asjp.cerist.dz/en/article/78365

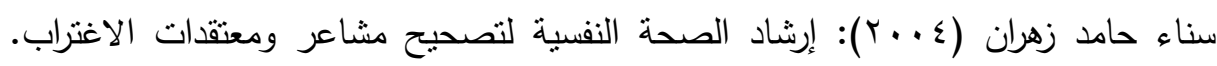

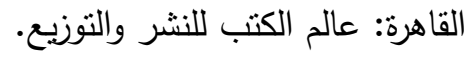

عبد الرحمن عدس ومحي الدينتوق (991 ()): الددخل الى علم النفس، دار الفكر للطباعة، عمان.

عبد اللطيف محمد خليفة (ץ. (ץ): دراسات في سيكولوجية الاغتراب. القاهرة دار غريب للطباعة والنشر والتوزيع.

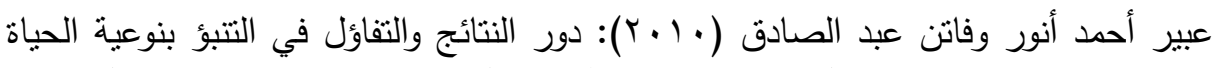

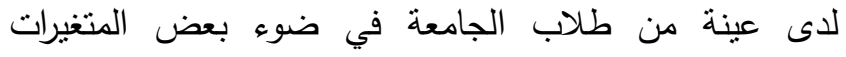

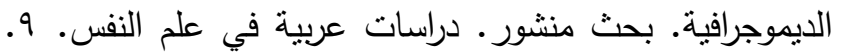

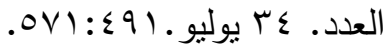

عبير أحمد أنور، فاتن عبد الصادق (• • ب): دور النتائج والتفاؤل في التتبؤ بنوعية الحياة

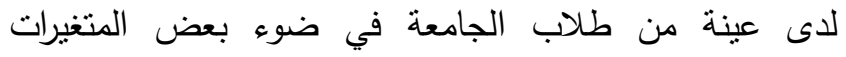
الديموجرافية. بحث منشور • دراسات عربية في في علم في النفس. 9.

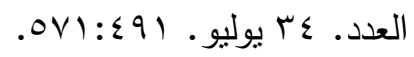

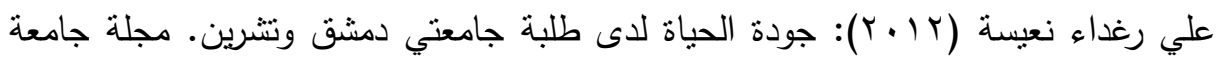

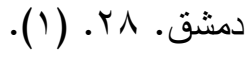




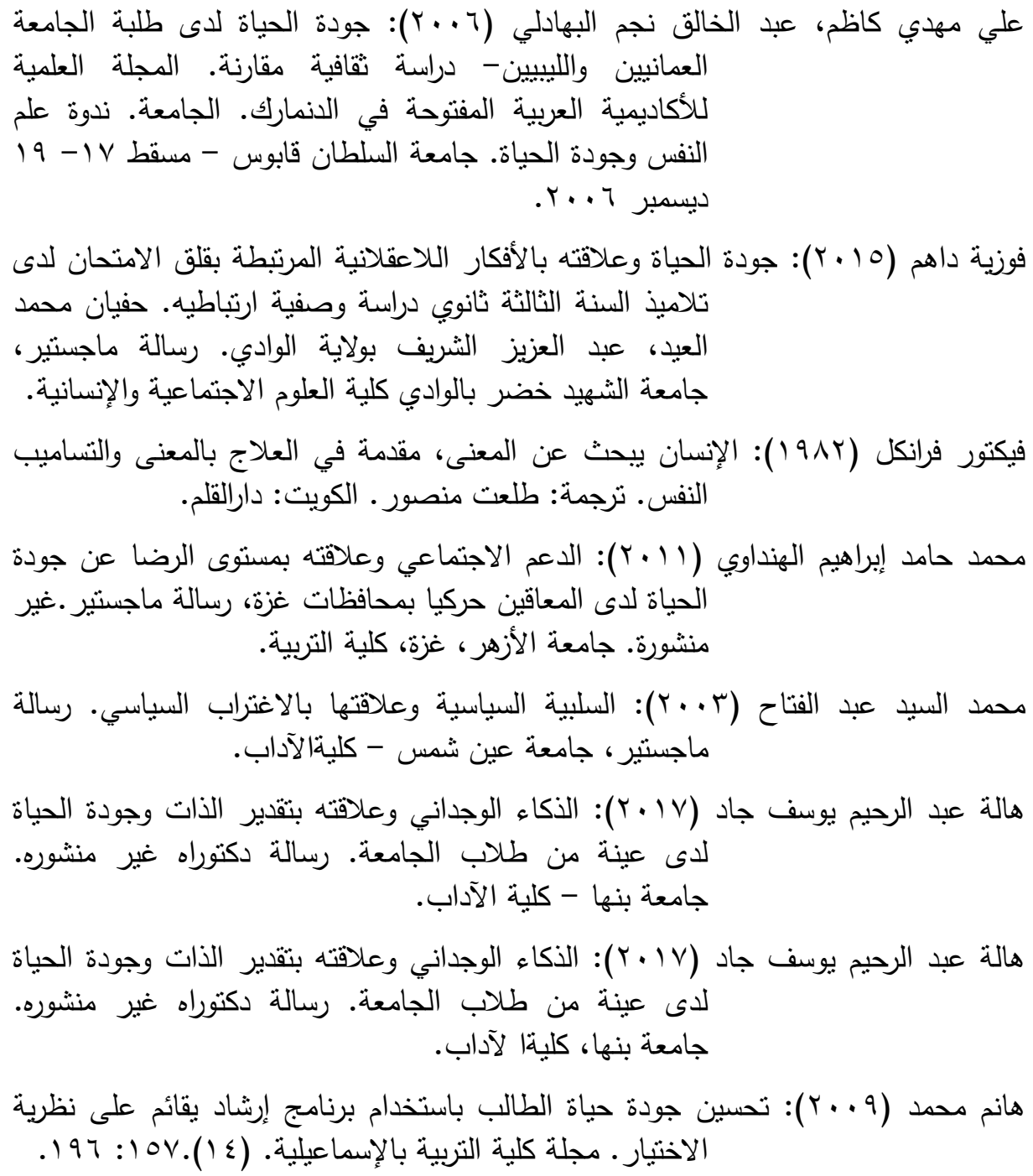

Pantoja A. \& Segura G. (2002): Descriptive Representation in the Statehouse and Political Alienation among of the Midwestern, Political Science Association. Chicago. April 25-28. Online version of this article can be found at: www.uiowa.edu/c030319/pdfs/descreb.pdf 


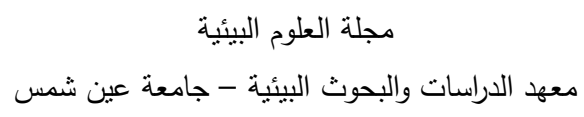

Ring, L. (2007): Quality of Life: In S. Ayers, A Boum, C.Mc Manus, S., Newman, K. Wallston. J. Weinman, R. West (Eds) Cambridge Handbook of Psychology. Health and Medicine, Cambridge University.

Shek, D. T. (1993): The Chinese purpose in life test and Psychological well-being in Chinese college students. International Forum for Logotherapy 16. (11). $35-42$

\title{
QUALITY OF LIFE AND ITS RELATION TO COMMUNITY ALIENATION -A COMPARATIVE STUDY IN DIFFERENT ENVIRONMENTS
}

\section{Enas El-Telawy ${ }^{(1)}$; Ahmed M. Al Ateeq ${ }^{(1)}$ \\ Mohamed A. El Tayeb ${ }^{(2)}$ and Saleh S. ${ }^{(3)}$}

1) Institute of Environmental Studies and Research, Ain Shams University 2) Faculty of Education, former University of Tanta 3) Faculty of Arts, Ain Shams University

\begin{abstract}
The objective of the study is to try to identify the differences between the study population of the urban environment (upper, middle and lower) in the quality of life variable in its sub-dimensions, and the five major personality factors as well as the variable of community alienation. In order to investigate the hypotheses of the current study, the comparative descriptive approach was used to describe the phenomenon in question, "Quality of Life and its Relation to Community Alienation". The study sample consists of (300) male and female participants from the urban environment (upper, middle and lower), with (100 participants) each. Class, income levels, and

$$
\text { المجلد السابع والأربعون، الجزء الثالث، سبتمبر } 9 \text {. }
$$


education The study tools were: Quality of Life Standard (Prepared by: Researcher), List of Five Major Personality Factors (Prepared by: Costa and Macri), Community Exile Scale (Prepared by: Researcher)

The study found the following results: Differences in the quality of life and its sub-dimensions (physical safety, mental health, social relations and communication with others, time management, proportionality, and sufficiency) towards the upper urban environment, and differences in neural variables and societal alienation towards the urban environment World. There are statistically significant differences in (goodness, conscience alertness, and societal alienation) in the direction of the sample female expatriate community. There is no relationship between alienation and the five major personality factors, while there is a strong inverse relationship between community alienation and all dimensions of the quality of life variable (physical safety, mental health, social relations and communication with others, time management and total quality of life). This suggests that rates of alienation in society may increase with lower quality of life, and vice versa.

The most important recommendations of the study: to study the role of social education institutions, "the family, educational institutions, peer groups, the media and political parties" that transfer knowledge, instill and develop values, and develop community participation skills. Interest in the study of marginalized groups, and study the social marginalization as a framework for the interpretation of violence and extremism that may result from the feeling of alienation. 